\title{
Subsistencia, movilidad y adaptación al medio de los cazadores-recolectores gravetienses en el sector occidental de la región cantábrica: la cueva de Coímbre (Asturias)*
}

\author{
Subsistence, mobility and environmental adaptation of the Gravettian hunter-gatherers \\ in the western part of Cantabria: Coímbre cave (Asturias)
}

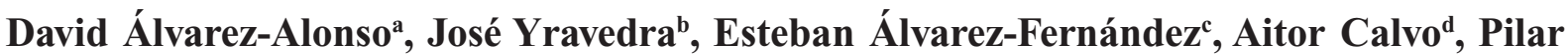 \\ Carrale, María José Iriarte Chiapusso $^{\mathrm{f}}$, Jesús F. Jordá Pardog ${ }^{\mathrm{g}}$, Carmen Seséh, Paloma \\ Uzquiano $^{i}$ y Álvaro Arrizabalagad
}

\section{RESUMEN}

En el trabajo presentamos el nivel gravetiense de Coímbre, uno de los contados ejemplos de esta cronología en el centro-occidente cantábrico. Se trata de uno de los yacimientos de mayor interés para el análisis del Gravetiense cerca de su margen occidental de expansión por el continente europeo. Mediante el análisis arqueozoológico y tafonómico de la fauna, de la industria lítica, los restos arqueobotánicos, la interpretación de la secuencia arqueológica y sedimentológica, y la obtención de dataciones AMS, se han podido analizar las ocupaciones gravetienses de Coímbre bajo una perspectiva territorial, donde las estrategias de susbsistencia desarrolladas son determinantes para interpretar el tipo de ocupación existente. En el marco de la región cantábrica, podemos interpretar la existencia de un patrón de movilidad y subsistencia determinado, desarrollado por estas poblaciones humanas, que se manifiesta como una ocupación efímera, de tipo logístico y puntual, ligada posiblemente con un eje de tránsito en sentido este-oeste. Esto supone uno de los elementos de mayor interés que aporta este estudio.

\begin{abstract}
Coimbre is one of the few Gravettian sites the middle-western part of Cantabria. It is one of the most interesting sites for the analysis of the Gravettian close to
\end{abstract}

* Esta investigación se ha realizado en el marco del proyecto de investigación "Paleocología y poblamiento en la cuenca media del Cares: la cueva de Coímbre (Besnes, Peñamellera Alta)" que ha sido financiado por la Fundación María Cristina Masaveu Peterson.

a Dpto. de Prehistoria y Arqueología, UNED-Asturias. Avda. Jardín Botánico 1345. 33203 Gijón, Asturias. Correo e.: dalvarez@ gijon.uned.es http://orcid.org/0000-0002-5752-9007.

b Dpto. de Prehistoria, Universidad Complutense de Madrid. Profesor Aranguren s/n 28040 Ciudad Universitaria, Madrid. Correo e.: jyravedra@ghis.ucm.es http://orcid.org/0000-0002-4323-3379.

c Dpto. de Prehistoria, Historia Antigua y Arqueología, Universidad de Salamanca. C/ Cerrada de Serranos s/n. 37002 Salamanca. Correo e.: epanik@usal.es http://orcid.org/0000-0002-7895-3421.

d Dpto. de Geografía, Prehistoria y Arqueología, Universidad del País Vasco UPV/EHU. Correos e.: aitor.calvo@ehu.eus http:// orcid.org/0000-0002-3753-8731 (AC); alvaro.arrizabalaga@ehu.eus http://orcid.org/0000-0001-6127-2972 (AA).

e Dpto. de Geología y Geoquímica. Universidad Autónoma de Madrid UAM. Campus de Cantoblanco. 28049 Madrid. Correo e.: pilar.carral@uam.es http://orcid.org/0000-0002-6289-691X.

${ }^{\mathrm{f}}$ IKERBASQUE/Área de Prehistoria, Universidad del País Vasco UPV/EHU. Correo e.: mariajose.iriarte@ehu.eus http://orcid. org/0000-0002-4409-2408.

g Laboratorio de Estudios Paleolíticos. Dpto. de Prehistoria y Arqueología. UNED. Senda del Rey, 7. Ciudad Universitaria. 28040 Madrid. Correo e.: jjorda@geo.uned.es http://orcid.org/0000-0002-3937-9199.

${ }^{\text {h }}$ Dpto. de Paleobiología, Museo Nacional de Ciencias Naturales-CSIC. C/ José Gutiérrez Abascal 2. 28006 Madrid. Correo e. c.sese@mncn.csic.es http://orcid.org/0000-0002-6833-1901.

i Universidad Nacional de Educación a Distancia UNED. Correo e.: p_uzquiano@hotmail.com http://orcid.org/0000-0002-23229225

Recibido 2-IX-2016; aceptado 8-XI-2016.

Copyright: (C) 2017 CSIC. Este es un artículo de acceso abierto distribuido bajo los términos de una licencia de uso y distribución Creative Commons Attribution (CC-by) España 3.0. 
the boundary of its western expansion in Europe. Zooarchaeological and taphonomical study of the faunal and archaeobotanical remains and the lithic industry and the interpretation of its AMS-dated archaeological and sedimentological sequence make it possible to analyse the Gravettian settlement in Coimbre cave using a territorial perspective. The subsistence strategies developed in Coimbre have been determinant in the interpretation of its occupation patterns. Thus, we can assess the existence of the specific mobility and subsistence patterns developed by these human groups in the framework of Cantabria. This pattern shows an ephemeral logistic and punctual occupation of the cave, probably linked to an eastern-western corridor. This is one of the paper's most interesting contributions.

Palabras clave: Paleolítico superior; Cornisa Cantábrica; AMS; Arqueozoología; Arqueobotánica; Industria lítica.

Key words: Upper Palaeolithic; Cantabria; AMS; Zooarchaeology; Archaeobotany; Lithic Industry.

\section{INTRODUCCIÓN}

El Gravetiense se presenta como un contexto crono-cultural con un notable desequilibrio en la distribución y número de yacimientos a lo largo de la región cantábrica. Hay un número bajo de registros en su extremo occidental, un discreto volumen de los mismos en el extremo oriental y una notable variedad y densidad de restos en el ámbito pirenaico (Heras et al. 2012a). Esto se debe, fundamentalmente, a la tardía adscripción al Gravetiense de las primeras evidencias documentadas, y únicas hasta bien entrada la década de 1980, en la parte occidental cantábrica. Son los niveles H y G de Cueto de la Mina (Jordá 1963, 1969), inicialmente asignados por su excavador al Auriñaciense superior (Vega del Sella 1916) a partir del modelo evolutivo de Breuil (Arrizabalaga 1998), y que F. Jordá (1963) englobó en el periodo "Gravetense". La presencia de Gravetiense en esta parte de la región cantábrica se cuestionó durante décadas. Los escasos restos tipológicamente adscribibles a esta etapa se fueron incluyendo en un Auriñaciense superior (según Breuil) o Perigordiense superior (según el modelo de Peyrony) cuya relación crono-espacial era muy difusa con respecto al Auriñaciense clásico (Jordá 1976; Bernaldo de Quirós 1982). Las excavaciones en el abrigo de La Viña (Fortea 1992), la cueva de Llonín, a comienzos de la década de 1990 (For- tea et al. 1995) y el Cueto de la Mina (Rasilla 1990), se incorporarán a las citadas evidencias del tecnocomplejo en la zona occidental cantábrica.

Ya en la década del 2010 van aumentando los yacimientos gravetienses, gracias la incorporación de Llonín (Rasilla y Santamaría 2006; Martínez y Rasilla 2013; Martínez 2015 ${ }^{1}$ y Sopeña (Pinto et al. 2012), y al descubrimiento y excavación del nivel Co.B.6 de Coímbre en 2012. Todos ellos componen el repertorio asturiano de evidencias. Salvando algunas referencias previas a La Viña y Cueto de la Mina (Rasilla y Hoyos 1988; Rasilla 1990; Fortea 1992), la sistematización del Gravetiense en Asturias es muy reciente. En 2017 se publicará el primer estudio completo y detallado de la ocupación gravetiense en la zona B de Coímbre (Álvarez-Alonso e Yravedra e. p.). Prueba del gran impulso de las investigaciones sobre el Gravetiense cantábrico en los últimos veinte años son las importantes síntesis de ámbito tanto estrictamente cantábrico (Arrizabalaga 19952; Rasilla y Straus 2004; Heras et al. 2012a; Arrizabalaga y Peña 2013; Bradtmöller 2014; Martínez y Rasilla 2013; Martínez 2015³) como pirenaico (Foucher 2013). Además han visto la luz numerosas investigaciones centradas en secuencias o yacimientos de la zona central y oriental de la región como Altamira, El Cuco, El Castillo, Mugarduia Sur, Aldatxarren, Ametzagaina, Alkerdi o Irikaitz, entre otros (Sáenz de Buruaga 2008; Cava et al. 2009; Arrizabalaga e Iriarte 2011; Bernaldo de Quirós et al. 2013; Calvo et al. 2013; Heras et al. 2013b; Rasines y Muñoz 2013; Arrizabalaga et al. 2014; Cava 2014).

\section{LOCALIZACIÓN DE COÍMBRE E HISTORIA DE LA INVESTIGACIÓN}

La cueva de Coímbre se sitúa en las cercanías de Besnes, un barrio perteneciente a la localidad de Alles (Peñamellera Alta, Asturias, España). Orientada al SO, sus coordenadas UTM son

\footnotetext{
${ }^{1}$ Martínez Fernández, L. 2015: El Gravetiense en el sector occidental cantábrico y sus conexiones pirenaicas. Tesis doctoral inédita. Universidad de Oviedo. Oviedo.

2 Arrizabalaga, A. 1995: La industria lítica del Paleolítico superior inicial en el oriente cantábrico. Tesis doctoral inédita. Universidad del País Vasco. Vitoria.

${ }^{3}$ Véase n. 1.
} 
X.363.165; Y.4.798.482; Z.145, Huso 30 (WGS 84). El karst de Coímbre se abre en la ladera SO del monte Pendendo (529 m), en el pequeño valle que forma el río Besnes, unos $800 \mathrm{~m}$ antes de su desembocadura en el Cares. La cueva se ubica, por tanto, en el curso medio-bajo del valle del Cares, en la zona centro-occidental de la región cantábrica. Las altitudes del medio circundante superan los $1.000 \mathrm{~m}$ pero está relativamente próxima a la costa actual (Fig. 1).

La cueva era ampliamente conocida en la zona desde antaño, pero no salta a la luz pública hasta el 4 de abril de 1971, cuando se descubren grabados paleolíticos en su interior (Moure y Gil 1972). Entonces se realiza una primera documentación de su arte rupestre y una valoración preliminar del yacimiento, situado en la sala principal (Moure y Gil 1974; Álvarez-Alonso et al. 2009). El yacimiento arqueológico aparece en dos áreas, A y $\mathrm{B}$, bien diferenciadas y sin conexión entre sus depósitos sedimentarios. Nunca fueron objeto de excavaciones, aunque sí de numerosas recogidas superficiales y de un constante expolio en la zona A, previo al cierre completo de la cavidad a comienzos de la década de 1980. En estos primeros años, las valoraciones preliminares se centraron en algunas piezas halladas en superficie que in-

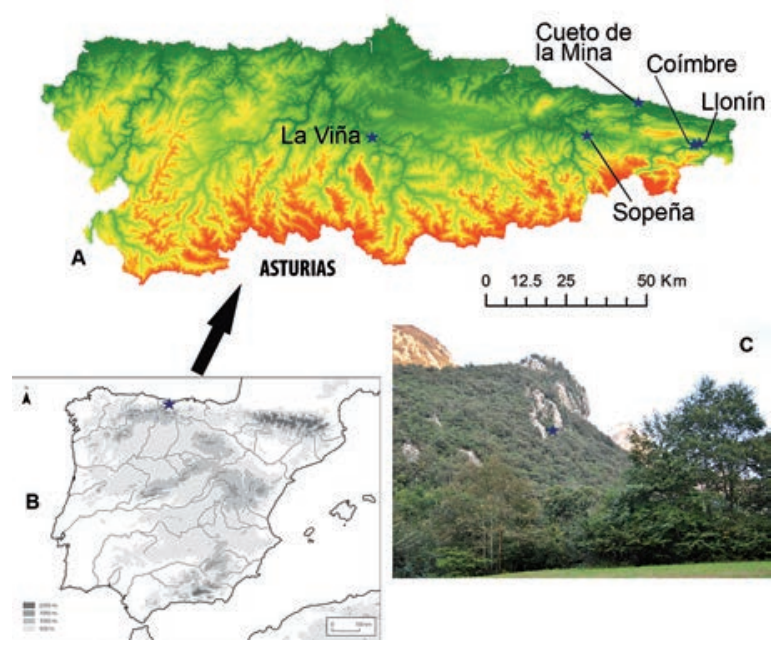

Fig. 1. Yacimientos gravetienses de Asturias (A); Localización de la cueva de Coímbre (Peñamellera Alta, Asturias) en la península ibérica (B); vista de la Pica de Coímbre, en la parte occidental del Monte Pendendo, donde se sitúa la cueva (C). vitaban a hablar de una cronología situada entre el Magdaleniense inferior/medio y el Aziliense (Utrilla 1981).

El yacimiento de la cueva de Coímbre, salvo su arte parietal, se sumió en un largo letargo hasta 2008, cuando iniciamos un proyecto de investigación centrado en la excavación y revisión del arte parietal, del cual se han ido avanzando periódicamente resultados preliminares (ÁlvarezAlonso et al. 2009, 2013b; Álvarez-Alonso et al. 2011; Álvarez-Alonso et al. 2014; ÁlvarezAlonso et al. 2016; Yravedra et al. 2016). En 2017 la publicación de una monografía aunará los resultados de todas las investigaciones efectuadas en la zona B de la cueva de Coímbre (Yravedra et al. e.p.).
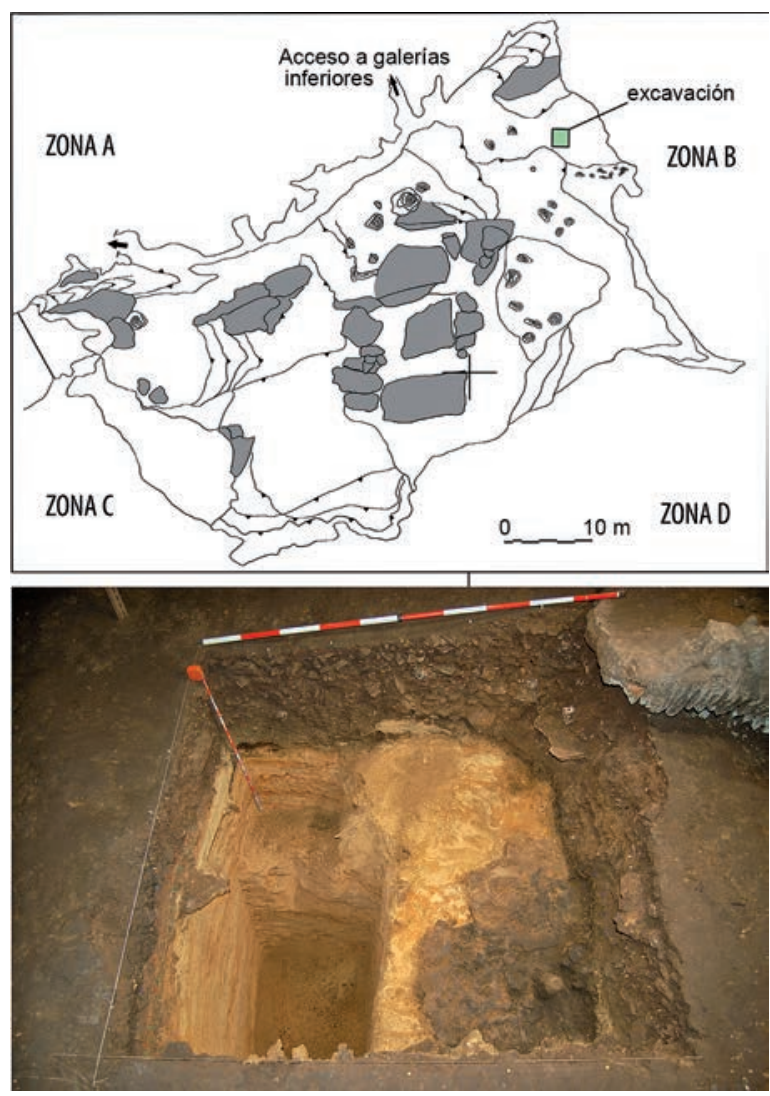

Fig. 2. Planta de la sala de entrada de la cueva de Coímbre (Peñamellera Alta, Asturias), en cuyo sector B se localiza el área de excavación donde se identificó el nivel gravetiense. Las zonas sombreadas en gris son bloques (arriba); excavación al final de la campaña de 2012 (abajo). 


\subsection{La excavación}

Antes de comenzar las excavaciones en 2008, se topografió en detalle la sala principal que, debido a sus grandes dimensiones y complejidad, fue dividida en cuatro sectores (A - D) para proceder a su estudio (Fig. 2). Las zonas A y B presentan importantes depósitos sedimentarios con distintas ocupaciones paleolíticas. En cinco campañas (2008 a 2012) se excavaron $4 \mathrm{~m}^{2}$ en el sector B, situado al interior de la sala de entrada. En 2012, se descubrió y excavó el nivel Co.B.6 (ÁlvarezAlonso et al. 2009, 2013b).

Además del nivel gravetiense, objeto de este trabajo, la cueva aloja un rico yacimiento con niveles del Magdaleniense arcaico, inferior, medio y superior, cuya completa crono-estratigrafía ya ha sido publicada (Álvarez-Alonso et al. 2011; Álvarez-Alonso et al. 2013b; Álvarez-Alonso et al. 2016). Acompaña esta secuencia un importante número de manifestaciones rupestres cuya cronología relativa, con las reservas oportunas, se situaría entre el Magdaleniense inferior y el Magdaleniense reciente (Moure y Gil 1974; ÁlvarezAlonso et al. 2014).

\section{LA SECUENCIA CRONO-ESTRATIGRÁFICA Y PALEOAMBIENTAL}

Los $4 \mathrm{~m}^{2}$ excavados en Coímbre B permitieron definir una estratigrafía muy compleja por la concurrencia de factores de origen natural y antrópico, ya explicados en detalle (Álvarez-Alonso et al. 2013b). El depósito arqueológico contiene cinco niveles arqueológicos diferentes, circunscritos a los primeros $80-70 \mathrm{~cm}$ de la secuencia. Esta alcanza una profundidad máxima de más de $230 \mathrm{~cm}$ (Álvarez-Alonso et al. 2013b; Álvarez-Alonso et al. 2016).

\subsection{La secuencia estratigráfica}

La sedimentación conocida en la zona $\mathrm{B}$, situada al fondo de la sala de entrada de la cueva, comienza con un potente nivel de arenas estériles (Co.B.7) formado por una actividad fluvial permanente. Hacia el 29 ka cal BP, el flujo de agua se vuelve más esporádico y sigue activo varios miles de años más, hasta cesar por completo durante las fases iniciales del Magdaleniense. Las primeras ocupaciones tienen lugar durante las últimas pulsaciones de este flujo hídrico, en un periodo de intermitencia que favorece el asentamiento humano directamente sobre el lecho de arenas. El nivel Co.B.6 se asienta tanto sobre las arenas del nivel Co.B.7, como sobre varios espeleotemas y placas desprendidas del techo de la cavidad. Su caída sobre el sustrato arenoso denota un evento de importante actividad gravitacional en el interior de la cueva. Está cubierto por otro nivel de arenas estériles (Co.B.5), similar al inferior (Co.B.7) (Álvarez-Alonso et al. 2013b; ÁlvarezAlonso et al. 2016).

Dentro del nivel Co.B.5, y fruto de uno de esos momentos de cese de la actividad fluvial, tuvo lugar un breve asentamiento que únicamente nos ha dejado un hogar. Su datación en un momento inicial del Magdaleniense, 20730-20270 cal BP, sirve para establecer una cronología mínima ante quem para el sellado del nivel Co.B.6. Sobre este estrato se sitúa el resto de niveles magdalenienses hasta finalizar la presencia humana, muy intensa durante el Magdaleniense superior, en esta parte de la cueva (Álvarez-Alonso et al. 2016) (Fig. 3). La tabla 1 describe de techo a muro los niveles de la secuencia estratigráfica.

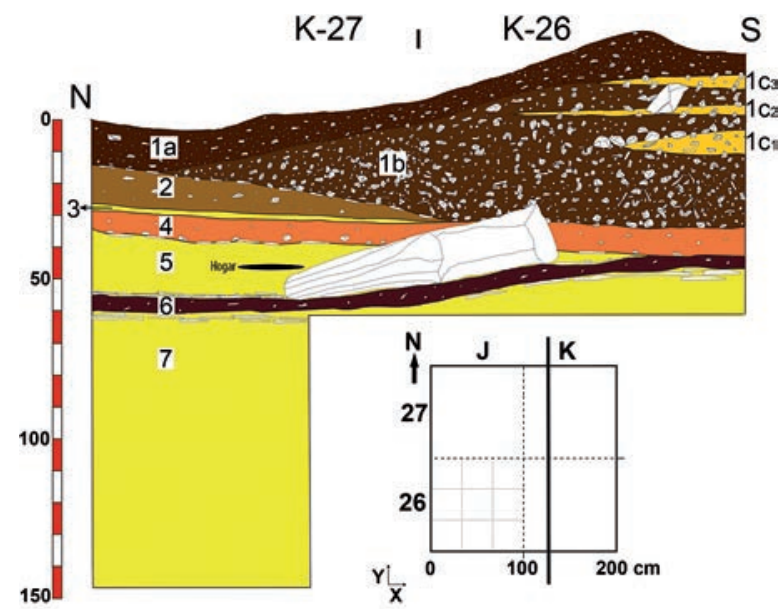

Fig. 3. Perfil estratigráfico oeste de la zona B de la cueva de Coímbre (Peñameller Alta, Asturias). Perfil estratigráfico longitudinal de la banda K (arriba). Magdaleniense superior (nivel 1); Magdaleniense medio (nivel 2); Magdaleniense inferior (nivel 4); Magdaleniense arcaico (dentro del nivel 5); Gravetiense (nivel 6). 


\begin{tabular}{|c|c|c|c|c|c|}
\hline \multicolumn{2}{|c|}{ Nivel } & Atribución & $\begin{array}{c}\text { Espesor } \\
\text { cm }\end{array}$ & Descripción & $\begin{array}{l}\text { Cronología } \\
\text { cal BP }\end{array}$ \\
\hline \multirow{3}{*}{$\vec{\varphi}$} & $1 \mathrm{a}$ & M. superior & $10-20$ & $\begin{array}{l}\text { Cantos y plaquetas de caliza autóctona (centil } 10 \mathrm{~cm} \text {, media } 2 \mathrm{~cm} \text { ), } \\
\text { angulosos, con las aristas romas, dispuestos de manera caótica. } \\
\text { Matriz de arenas y arcillas negras, con abundante materia orgánica. }\end{array}$ & \multirow{3}{*}{$15680-14230$} \\
\hline & $1 \mathrm{~b}$ & M. superior & $10-50$ & $\begin{array}{l}\text { Cantos (centil } 20 \mathrm{~cm} \text {, media } 1 \mathrm{~cm} \text { ) y plaquetas de caliza muy frag- } \\
\text { mentadas y de tamaño centimétrico, con matriz limoso-arcillosa } \\
\text { de color negro, rica en materia orgánica. Con geometría tabular y } \\
\text { disposición horizontal paralela a la superficie deposicional. }\end{array}$ & \\
\hline & $1 \mathrm{c}$ & M. superior & $<5$ & $\begin{array}{l}\text { Tres pequeñas cuñas de arena fina de cuarzo }(1 \mathrm{c} 1,1 \mathrm{c} 2,1 \mathrm{c} 3) \text { de } \\
\text { color amarillo, que se intercalan dentro del nivel Co.B.1b. Ninguno } \\
\text { sobrepasa } \operatorname{los} 5 \mathrm{~cm} \text { de espesor máximo. }\end{array}$ & \\
\hline \multicolumn{2}{|l|}{ Co.B. 2} & M. medio & $0-10$ & $\begin{array}{l}\text { Arenas finas y muy finas de cuarzo, de color marrón oscuro, con } \\
\text { arcillas limosas y gravas. Con geometría lenticular, se acuñan } \\
\text { lateralmente hacia el sur erosionadas por el nivel suprayacente. A } \\
\text { techo presenta clastos y plaquetas dispuestas de forma horizontal } \\
\text { que lo separa claramente del nivel Co.B.1b. Su contacto con el } \\
\text { nivel infrayacente es muy neto. }\end{array}$ & $17160-15690$ \\
\hline \multicolumn{2}{|l|}{ Co.B.3 } & Estéril & $0-5$ & $\begin{array}{l}\text { Arenas de cuarzo de color amarillo, con gravas, limos gruesos } \\
\text { y arcillas. Su aspecto es masivo y arqueológicamente es estéril. }\end{array}$ & \\
\hline \multicolumn{2}{|l|}{ Co.B.4 } & M. inferior & $5-10$ & $\begin{array}{l}\text { Arenas de cuarzo de color marrón oscuro, con gravas, limos } \\
\text { gruesos y arcillas, de aspecto masivo y disposición horizontal y } \\
\text { paralela a la superficie deposicional. }\end{array}$ & $19970-18720$ \\
\hline \multicolumn{2}{|l|}{ Co.B.5.1 } & M. arcaico & $0-2$ & Pequeño horizonte con un hogar, dentro del nivel Co.B.5. & $20730-20270$ \\
\hline \multicolumn{2}{|l|}{ Co.B.5 } & Estéril & $0-20$ & $\begin{array}{l}\text { Arenas de cuarzo de color amarillo, con limos gruesos y arcillas, } \\
\text { dispuestas con laminación paralela y arqueológicamente estériles. } \\
\text { Se acuña lateralmente hacia el sur. }\end{array}$ & \\
\hline \multicolumn{2}{|l|}{ Co.B.6 } & Gravetiense & $0-10$ & $\begin{array}{l}\text { Arenas de cuarzo, finas a muy finas y color marrón oscuro, con } \\
\text { gravas, limos y arcillas. Dispuestas entre dos lechos de pequeñas } \\
\text { plaquetas estalagmíticas. Geometría tabular y contactos muy netos. }\end{array}$ & $29660-28560$ \\
\hline \multicolumn{2}{|l|}{ Co.B.7 } & Estéril & $>180$ & $\begin{array}{l}\text { Arenas de cuarzo finas y muy finas, de color amarillo, con muy } \\
\text { escasa presencia de gravas, limos y arcillas. Internamente se dis- } \\
\text { ponen con laminación paralela centimétrica en la que alternan } \\
\text { láminas de arenas finas con otras de arenas finas y muy finas. }\end{array}$ & \\
\hline
\end{tabular}

Tab. 1. Descripción de la secuencia estratigráfica de la zona B de la cueva de Coímbre (Peñamellera Alta, Asturias). M Magdaleniense.

Durante los trabajos geoarqueológicos en Coímbre $\mathrm{B}$, se tomaron muestras para análisis sedimentológicos (textura, residuo insoluble y mineralogía - DRX), edafológicos (color, $\mathrm{pH}$, carbonatos totales - $\mathrm{CaCO} 3$ - materia orgánica, carbono orgánico), así como granulométricos. Los resultados han servido para caracterizar la composición de los niveles documentados e interpretar sus procesos de formación.

El nivel Co.B.6, según su caracterización litológica, es una capa de 0 a $10 \mathrm{~cm}$ de arenas de cuarzo, finas a muy finas, de color marrón oscuro, con gravas, limos y arcillas, que se disponen entre sendos lechos de pequeñas plaquetas estalagmíticas a muro y a techo, con geometría tabular y contactos muy netos, tanto superior como inferior. El sedimento del nivel Co.B.6 pertenece al grupo de las arenas fangosas con apenas gravas (gravelly muddy sand) y presenta unos colores marrones más o menos intensos con matices entre 7,5YR y 10YR — según el código Munsell—, así como clastos de rocas autóctonas (calizas, espeleotemas) y sedimentos finos carbonatados (calcita). Este nivel se asienta directamente sobre el paquete de arenas estériles Co.B.7, un depósito de $180 \mathrm{~cm}$ visibles de arenas de cuarzo finas y muy finas, de color amarillo, con muy escasa presencia de gravas, limos y arcillas. Estas internamente se disponen con laminación paralela centimétrica, alternándose láminas de arenas finas con otras de 
arenas finas y muy finas que componen una sucesión de pequeñas secuencias granodecrecientes.

En resumen, podemos afirmar que el nivel Co.B.6 está bien delimitado estratigráficamente entre dos niveles de arenas estériles, que lo han sellado e individualizado, descartándose cualquier tipo de contaminación de materiales procedentes de ocupaciones posteriores. A su vez la datación netamente posterior aportada por el hogar documentado en la unidad 5.1 permite establecer una cronología máxima para el comienzo de la ocupación magdaleniense. Se trata, por tanto, de un nivel bien aislado que además ofrece sólidas garantías cronológicas para contextualizar las ocupaciones gravetienses en el centro-occidente cantábrico.

\subsection{Dataciones C14 AMS y posición cronoestratigráfica}

En el nivel Co.B.6 se recogieron tres muestras óseas que se enviaron a datar por C14-AMS en el laboratorio Beta Analytic (Miami, EE.UU). Se seleccionaron fragmentos de diáfisis de ungulado de pequeño tamaño, cuya determinación taxonómica es difícil por la elevada fragmentación de la muestra faunística, pero que probablemente sean de cabras, a tenor de la fauna presente en el nivel. La gran similaridad de los resultados del C14-AMS (fechas e incluso relación C13) que se solapan entre sí aporta una cronología bastante bien acotada. Las tres fechas se agrupan en una horquilla temporal calibrada que se extiende entre 29660 y 28560 cal BP (Tab. 2). A nuestro juicio, la buena resolución cronológica para el nivel es coherente, no solo con el contexto arqueológico, sino también con la sucesión crono-estratigráfica obtenida para la secuencia estratigráfica de la zona B (Álvarez-Alonso et al. 2016). A partir de los datos cronológicos obtenidos, la primera ocupación humana identificada en este sector de la cueva sucedió en un periodo moderadamente templado (GI 4), posterior al episodio árido Heinrich 3 (H 3), dentro de unas características generales frías, que se traducen en medios vegetales mucho más abiertos, como veremos más adelante.

Los datos obtenidos en la secuencia de Coímbre $\mathrm{B}$ concuerdan con otros registros cronológicos del Gravetiense cantábrico. En el contexto más inmediato, el extremo occidental cantábrico, tenemos cuatro dataciones radiocarbónicas asignables, sin dudas, al Gravetiense procedentes de La Viña, Sopeña y Cueto de la Mina. El paralelo entre la del nivel IX de La Viña, 24640 \pm 190 BP (Wood et al. 2014), y las obtenidas en el nivel Co.B.6 de Coímbre debe matizarse, dado que la primera se realizó a través del método de ultrafiltración, donde el tratamiento previo de la muestra y el propio método difieren de los empleados en las dataciones de Coímbre. La fecha del nivel II de Sopeña, $24300 \pm 170 \mathrm{BP}$, procede de un contexto estratigráfico alterado (Pinto et al. 2012) mientras la de su nivel X, 23550 $180 \mathrm{BP}$, tiene una correspondencia similar, aunque ligeramente más alejada en el tiempo. En los demás yacimientos con niveles gravetienses datados en la cornisa cantábrica apenas encontramos fechas equiparables a las de Coímbre. Solo cabría mencionar con cierta seguridad algunas dataciones de los niveles $\mathrm{V}$ y VI del sector interior de Aitzbitarte III y del nivel IV del sector exterior (Altuna 1992; Altuna et al. 2011). El número es muy bajo, dado el total de $c a .60$ dataciones disponibles para la cornisa cantábrica, y manifiesta una importante falta de evidencias cronológicas en torno a esta fecha de $24 \mathrm{ka}$ BP.

Tras evaluar el registro de dataciones existente para el Gravetiense cantábrico y eliminar aque-

\begin{tabular}{|c|c|c|c|c|c|c|c|c|}
\hline & & & & & & & INTCAL 2013 & CalPal 2007 Hulu \\
\hline Nivel & Asignación & Muestra & Cod. Lab. & $\begin{array}{c}\text { Fecha } \\
\text { C14 }\end{array}$ & DT & $\begin{array}{l}{ }^{13} \mathrm{C} /{ }^{12} \mathrm{C} \\
(\mathrm{o} / \mathrm{oo})\end{array}$ & $\begin{array}{c}\text { CalAge p(95\%) } \\
{[\text { calBP }(0=A D 1950)]}\end{array}$ & $\begin{array}{c}\text { CalAge p(95\%) } \\
{[\text { calBP }(0=A D 1950)]}\end{array}$ \\
\hline Co.B.6 & Gravetiense & hueso & Beta-322481 & 24410 & 120 & $-19,5$ & $28760-28120$ calBP & $29880-28880$ calBP \\
\hline Co.B.6 & Gravetiense & hueso & Beta-340006 & 24190 & 110 & $-20,9$ & $28560-27880$ calBP & $29740-28420$ calBP \\
\hline Co.B.6 & Gravetiense & hueso & Beta-340007 & 24260 & 110 & $-20,4$ & $28630-27950$ calBP & $29820-28500$ calBP \\
\hline
\end{tabular}

Tab. 2. Dataciones del nivel gravetiense Co.B.6 de la cueva de Coímbre (Peñamellera Alta, Asturias).

Trab. Prehist., 74, N. ${ }^{\circ}$ 1, enero-junio 2017, pp. 47-67, ISSN: 0082-5638

doi: $10.3989 /$ tp. 2017.12183 


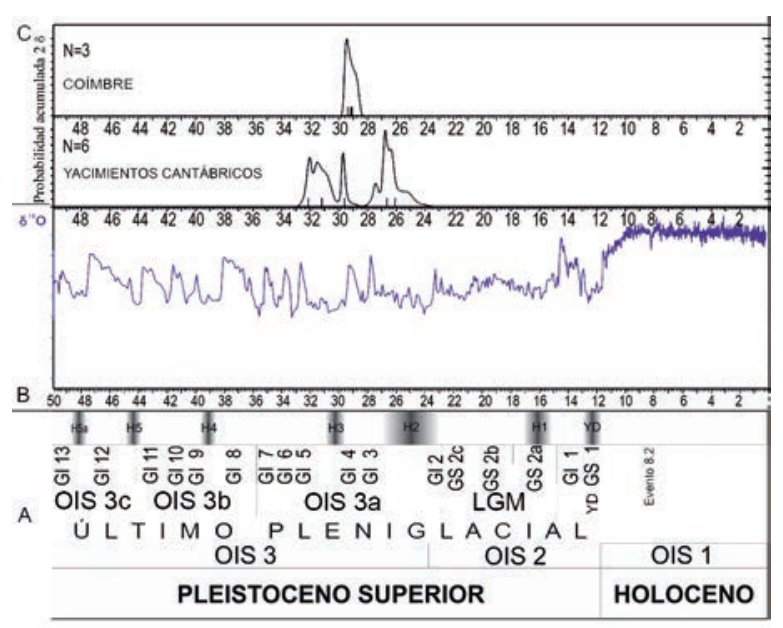

Fig. 4. Comparación de las dataciones del nivel Co.B.6 de Coímbre (Peñamellera Alta, Asturias) con las obtenidas para los niveles gravetienses de Cueto de La Mina VII, La Viña IX (Asturias), La Garma A (E y F), El Mirón 128 (Cantabria) y Alkerdi 2 (Navarra), enmarcadas en la escala cronoestratigráfica del Pleistoceno superior final. Elaboración propia a partir de Björck et al. 1998; Jordá Pardo et al. 2014; Shackleton y Opdyke 1973.

llas que ofrecen serias dudas sobre su contexto arqueológico o sobre la validez de los resultados radiométricos, hemos obtenido la siguiente gráfica (Fig. 4). En ella observamos cómo el nivel Co.B.6 de Coímbre parece alinearse con algunos niveles correspondientes a las últimas fases del Gravetiense en la región cantábrica. Además la gráfica sitúa la mayor parte de las evidencias de su extremo occidental, en el mismo contexto cronológico que Coímbre.

\subsection{El registro paleoambiental}

En el transcurso de la excavación se han recuperado restos faunísticos de pequeños mamíferos y aves, así como un número relativamente amplio de restos de madera carbonizada que nos ayudan a reconstruir el medio ambiente del entorno de Coímbre durante la ocupación gravetiense. Entre los micromamíferos se han contabilizado algunos ejemplares de Arvicola amphibius; Microtus gr. arvalis-agrestis; Microtus lusitanicus; Chionomys nivalis y de lepóridos (Oryctolagus cuniculus). En el nivel únicamente se han recuperado siete restos de aves de las especies Alectorix/perdis sp; Pyrrhocorax pyrrhocorax; Pyrrhocorax graculus y Corvidae indet. El grado de deterioro de los restos polínicos analizados ha impedido contar con excesiva información sobre el paisaje vegetal que existió durante la formación del nivel Co.B.6, salvo las evidencias antracológicas (Yravedra et al. 2016; Iriarte-Chiapusso et al. e. p.).

La ecología de los escasos restos de aves sedentarias recuperados nos sugiere la existencia de medios abiertos y despejados con poca vegetación, tanto pastizales como matorral bajo en la línea de lo apuntado por los restos antracológicos. Dentro de los córvidos, las dos especies de chovas (piquirroja y piquigualda) identificadas en el nivel habitarían en zonas abiertas (prados) y rocosas, mientras que las perdices escogerían herbazales amplios u otras cubiertas vegetales, no más altas que la altura del animal. La presencia de estas especies de aves apuntaría a unas condiciones medioambientales más frías que las actuales a pesar del relativo descenso del rigor climático, dentro del marco general en el que tuvo lugar la ocupación del yacimiento y atendiendo a su altitud y ubicación. Los datos de micromamíferos son compatibles con este paisaje.

Los recursos seleccionados por los habitantes gravetienses tuvieron como finalidad la alimentación, el combustible, etc. En el paisaje circundante de Coímbre los taxones de landa (sobre todo Fabaceae: Ulex y Cytisus) constituyeron el combustible mayoritario registrado con aparición también ocasional de leña de taxones como el madroño y el enebro. El potencial altamente inflamable y la combustión rápida hacen que estas leñosas sean idóneas para estancias breves e itinerantes como las efectuadas por los pastores en época reciente, a lo largo de la montaña cantábrica (Aseguinolaza et al. 1989). Esta particularidad sugiere que las ocupaciones debieron ser muy puntuales. Por otro lado, en las cercanías de la cueva, el predominio de los taxones de landa también se observa en el registro antracológico del nivel III Gravetiense del Abrigo de Sopeña (Asturias) (Uzquiano 2014).

En resumen, a pesar del contexto regional templado en el que se encuadran las ocupaciones humanas registradas en el nivel Co.B.6, los datos obtenidos muestran un paisaje abierto con predominio de especies de landa como Cytisus y Ulex, presencia de especies arbustivas Rhamus y Arbutus y especies arbóreas como Juniperus y 
Sorbus, que concuerda con la asociación faunística representada en el nivel. Ello sugiere unas condiciones más frías que las que se encuentran en la actualidad, con una cubierta vegetal poco densa y unos substratos silíceos sometidos a tasas de humedad elevada dada la abundancia de taxones de landa.

\section{ZOOARQUEOLOGÍA Y TAFONOMÍA DE LOS RESTOS FAUNÍSTICOS}

En el nivel Co.B.6 se han recuperado 12.804 fragmentos óseos, el 93,6\% de ellos quemados. Además el $97,8 \%$ son inferiores a $3 \mathrm{~cm}$ y el $58,6 \%$ (7.502 fragmentos) indeterminados. Entre las especies determinables se han identificado Bos/Bison, Equus ferus, Cervus elaphus y $\mathrm{Ca}$ pra pyrenaica. En cambio en el nivel Co.B.6 los grandes bóvidos (Bos/Bison) son el grupo más abundante con el 40\% del MNI (Tab. 3). Además, en líneas generales, los animales de talla grande considerando como tales los que superan los 600 $\mathrm{kg}$ de peso representan el $80 \%$ del NISP, mientras que los de talla pequeña (entre $25-125 \mathrm{~kg}$ ) son el $13 \%$. Esta tendencia es totalmente opuesta a la observada en los niveles magdalenienses donde, en coherencia con el entorno circundante de espacios montañosos, muy rocosos, abruptos y escarpados, la cabra es el animal más frecuente, alcanzando los animales de talla pequeña el 91\% del NR (Álvarez-Alonso et al. 2016; Yravedra et al. 2016; Yravedra et al. 2017). La representación faunística de grandes bóvidos en el Gravetiense resulta curiosa por su desajuste con el medio inmediato de la cueva de Coímbre. No se puede explicar en términos de especialización adaptativa al medio (Andrés-Herrero et al. e. p.).

El patrón de edad predominante en todos los taxones son los individuos adultos: grandes bóvidos $75 \%$, cabras $67 \%$, caballos y ciervos $100 \%$ (Tab. 3). Todos los taxones, incluidos los grandes bóvidos y caballos, están representados tanto por restos craneales, como axiales y apendiculares del esqueleto (Tab. 4). La abundancia de los dos últimos indicaría que los animales fueron transportados completos al yacimiento.

Los análisis tafonómicos muestran un elevado índice de fragmentación de los restos: el 97,8\% son inferiores a $3 \mathrm{~cm}$, el $93 \%$ de las diáfisis tiene

\begin{tabular}{|l|c|c|c|c|c|c|}
\hline \multirow{2}{*}{ Nivel Co.B.6 } & \multicolumn{3}{|c|}{ NR } & \multicolumn{3}{c|}{ MNI } \\
\cline { 2 - 7 } & NR & $\%$ & $\begin{array}{c}\text { \% sobre } \\
\text { Determinables }\end{array}$ & MNI & $\%$ & $\begin{array}{c}\text { Inf./ } \\
\text { Juv./ } \\
\text { Ad. }\end{array}$ \\
\hline Bos / Bison & 47 & 0,4 & 0,9 & 4 & 40,0 & $1 / 0 / 3$ \\
\hline Equus ferus & 6 & 0,0 & 0,1 & 1 & 10,0 & $0 / 0 / 1$ \\
\hline Indet T. Grande & 4148 & 32,4 & 78,2 & & & \\
\hline Cervus elaphus & 24 & 0,2 & 0,5 & 1 & 10,0 & $0 / 0 / 1$ \\
\hline Indet T. Mediana & 373 & 2,9 & 7,0 & & & \\
\hline Capra pyrenaica & 46 & 0,4 & 0,9 & 3 & 30,0 & $1 / 0 / 2$ \\
\hline Indet T. Pequeña & 658 & 5,1 & 12,4 & & & \\
\hline $\begin{array}{l}\text { Oryctolagus } \\
\text { cuniculus }\end{array}$ & 1 & 0,0 & 0,0 & 1 & 10,0 & $0 / 0 / 1$ \\
\hline Indeterminado & 7502 & 58,6 & & & & \\
\hline Total & $\mathbf{1 2 8 0 5}$ & $\mathbf{1 0 0 , 0}$ & & $\mathbf{1 0 , 0}$ & $\mathbf{1 0 0 , 0}$ & \\
\hline
\end{tabular}

Tab. 3. Nivel Gravetiense de la cueva de Coímbre (Peñamellera Alta, Asturias). Frecuencia de especies según el NR (número de restos) y el MNI (mínimo número de individuos), donde In: infantil; Juv: juvenil-adulto joven; Ad.; Indet T. grande son restos no identificables taxonómicamente, pero si asignables a animales de peso superior a $600 \mathrm{~kg}$; Indet Talla Mediana es lo mismo para animales de peso comprendido entre $125-600 \mathrm{~kg}$ y los de talla pequeña para los inferiores a $125 \mathrm{~kg}$.

un grado de circunferencia inferior al $25 \%$ y el $99 \%$ de los huesos representan menos de un $25 \%$ de su longitud total. La preservación de las superficies óseas es buena, sin apenas evidencias de weathering, ni alteraciones de tipo hídrico como pulidos, rodamientos, abrasiones, etc. La acción de los carnívoros es muy reducida, por lo que su impacto sobre el conjunto es insignificante.

El aporte antrópico a la cueva de la totalidad de la fauna del nivel gravetiense es indudable, lo cual se manifiesta en numerosas marcas y alteraciones térmicas (Tab. 5). Las marcas de percusión, localizadas sobre las diáfisis de los huesos largos, pretenden aprovechar el tuétano. Las de corte se corresponden con actividades y funciones variadas en distintos restos. Por ejemplo, las marcas de descarnado son frecuentes en costillas, vértebras y diáfisis de huesos largos, mientras que las de desarticulación se observan en epífisis distales de fémur de ciervo y cabra, en la parte distal de húmeros de grandes bóvidos, ciervos y cabras, y en tibias y meta-diáfisis de ciervos y grandes bóvidos. Las marcas de desollado, 


\begin{tabular}{|c|c|c|c|c|c|c|c|c|c|c|c|c|}
\hline \multirow{2}{*}{ Nivel Co.B.6 } & \multicolumn{3}{|c|}{ NR } & \multicolumn{3}{|c|}{ MNE } & \multicolumn{3}{|c|}{$\%$ NR } & \multicolumn{3}{|c|}{$\%$ MNE } \\
\hline & G & $\mathbf{M}$ & $\mathbf{P}$ & $\mathbf{G}$ & $\mathbf{M}$ & $\mathbf{P}$ & G & M & $\mathbf{P}$ & $\mathbf{G}$ & $\mathbf{M}$ & $\mathbf{P}$ \\
\hline Cuerno & 0 & 2 & 1 & 0 & 1 & 1 & 0 & 3 & 1 & 0 & 3 & 2 \\
\hline Craneal & 4 & 5 & 9 & 1 & 1 & 2 & 2 & 7 & 5 & 2 & 3 & 4 \\
\hline Maxilar & 0 & 0 & 4 & 0 & 0 & 1 & 0 & 0 & 2 & 0 & 0 & 2 \\
\hline Mandíbula & 3 & 2 & 5 & 1 & 1 & 3 & 2 & 3 & 3 & 2 & 3 & 6 \\
\hline Vértebra & 33 & 16 & 34 & 10 & 6 & 15 & 18 & 21 & 18 & 15 & 19 & 29 \\
\hline Costilla & 32 & 17 & 91 & 13 & 7 & 12 & 17 & 22 & 49 & 20 & 22 & 23 \\
\hline Escapula & 1 & 0 & 0 & 1 & 0 & 0 & 1 & 0 & 0 & 2 & 0 & 0 \\
\hline Húmero & 31 & 9 & 9 & 5 & 2 & 2 & 17 & 12 & 5 & 8 & 6 & 4 \\
\hline Radio & 4 & 3 & 4 & 1 & 1 & 2 & 2 & 4 & 2 & 2 & 3 & 4 \\
\hline Ulna & 4 & 0 & 1 & 1 & 0 & 1 & 2 & 0 & 1 & 2 & 0 & 2 \\
\hline Carpo & 3 & 2 & 1 & 3 & 2 & 1 & 2 & 3 & 1 & 5 & 6 & 2 \\
\hline Metacarpo & 5 & 0 & 1 & 2 & 0 & 1 & 3 & 0 & 1 & 3 & 0 & 2 \\
\hline Pelvis & 0 & 0 & 6 & 0 & 0 & 1 & 0 & 0 & 3 & 0 & 0 & 2 \\
\hline Fémur & 10 & 5 & 5 & 2 & 1 & 2 & 5 & 7 & 3 & 3 & 3 & 4 \\
\hline Tibia & 30 & 4 & 9 & 5 & 1 & 4 & 16 & 5 & 5 & 8 & 3 & 8 \\
\hline Fíbula & 0 & 2 & 0 & 0 & 2 & 0 & 0 & 3 & 0 & 0 & 6 & 0 \\
\hline Metatarso & 0 & 2 & 2 & 0 & 1 & 1 & 0 & 3 & 1 & 0 & 3 & 2 \\
\hline Metapodio & 3 & 1 & 0 & 0 & 0 & 0 & 2 & 1 & 0 & 0 & 0 & 0 \\
\hline Falange & 16 & 4 & 2 & 15 & 4 & 2 & 9 & 5 & 1 & 23 & 13 & 4 \\
\hline Sesamoideo & 6 & 2 & 1 & 6 & 2 & 1 & 3 & 3 & 1 & 9 & 6 & 2 \\
\hline Total & 185 & 76 & 185 & 66 & 32 & 52 & 100 & 100 & 100 & 100 & 100 & 100 \\
\hline & $\mathbf{G}$ & $\mathbf{M}$ & $\mathbf{P}$ & G & M & $\mathbf{P}$ & G & M & $\mathbf{P}$ & G & M & $\mathbf{P}$ \\
\hline Craneal & 7 & 9 & 19 & 2 & 3 & 7 & 4 & 12 & 10 & 3 & 9 & 14 \\
\hline Axial & 66 & 33 & 131 & 24 & 13 & 28 & 36 & 43 & 71 & 36 & 41 & 54 \\
\hline Apen. sup. & 79 & 23 & 28 & 14 & 7 & 11 & 43 & 30 & 15 & 21 & 22 & 21 \\
\hline Apen. inf. & 33 & 11 & 7 & 26 & 9 & 6 & 18 & 15 & 4 & 39 & 28 & 12 \\
\hline Ext. ant. & 48 & 14 & 16 & 13 & 5 & 7 & 55 & 52 & 42 & 65 & 50 & 47 \\
\hline Ext. post. & 40 & 13 & 22 & 7 & 5 & 8 & 46 & 48 & 58 & 35 & 50 & 53 \\
\hline
\end{tabular}

Tab. 4. Perfiles esqueléticos según el NR y el MNE del nivel Gravetiense de la cueva de Coímbre (Peñamellera Alta, Asturias) (modificado de Yravedra et al. 2016). G: animales de talla grande; M: animales de talla mediana; P: animales de talla pequeña; Apen. Sup.: Apendicular superior; Apen. Inf.: Apendicular inferior; Ext. Ant.: Extremidad anterior; Ext. Post.: Extremidad posterior.

poco frecuentes, se han observado en falanges de bóvidos, ciervos y en los cráneos de animales de pequeña talla. Sin lugar a dudas, la modificación más importante son las alteraciones térmicas: casi el $94 \%$ de la fauna ha estado expuesta directa o indirectamente al fuego. Las evidencias de crazing, fracturas poligonales y en mosaico sugieren que se quemaron en estado fresco. El $81 \%$ de los restos óseos con alteración térmica están carbonizados y quemados, con una coloración negra o blanca 


\begin{tabular}{|c|c|c|c|c|c|c|c|c|c|c|c|c|}
\hline \multirow{2}{*}{ Nivel Co.B.6 } & & & & & & & \multicolumn{6}{|c|}{ Alteraciones ligadas a la actividad humana } \\
\hline & NR & MT & MN & $\mathbf{W}$ & MD & $\%$ MD & MC & $\% \mathrm{MC}$ & PM & $\% \mathbf{P M}$ & Quemados & \%Quemados \\
\hline Bos / Bison & 47 & 2 & 2 & 1 & 2 & 5 & 12 & 28 & 4 & 9 & 31 & 66 \\
\hline Equus ferus & 6 & & & & & & & & & & 4 & 67 \\
\hline Cervus elaphus & 24 & 1 & 1 & 3 & & & 6 & 26 & 2 & 9 & 12 & 50 \\
\hline Capra pyrenaica & 46 & 4 & & 1 & & & 2 & 8 & 2 & 8 & 20 & 44 \\
\hline Ind. T. Grande & 4148 & 10 & 11 & 3 & & & 44 & 1 & 27 & 1 & 3.858 & 93 \\
\hline Ind. T. Mediana & 373 & 8 & 5 & 2 & 1 & 0.3 & 15 & 4 & 4 & 1 & 68 & 18 \\
\hline Ind. T. Pequeña & 658 & 3 & & 1 & 1 & 0.2 & 23 & 4 & 9 & 1 & 644 & 98 \\
\hline Indeterminado & 7.502 & 2 & 3 & 2 & & & 6 & & & & 7.351 & 98 \\
\hline Total & 12.805 & 31 & 27 & 13 & 4 & & 108 & 1 & 48 & & 11.988 & 94 \\
\hline
\end{tabular}

Tab. 5. Huesos con alteraciones del nivel Co.B.6 de la cueva de Coímbre (Peñamellera Alta, Asturias), donde MT: Huesos con marcas de trampling, MN: Huesos con pigmentación por manganeso; W: Huesos con algo de weathering en grado suave; MD: Marcas de diente; MC: huesos con marcas de corte; PM: huesos con marcas de percusión; Quemado: huesos con alteraciones térmicas (modificado de Yravedra et al. 2016).

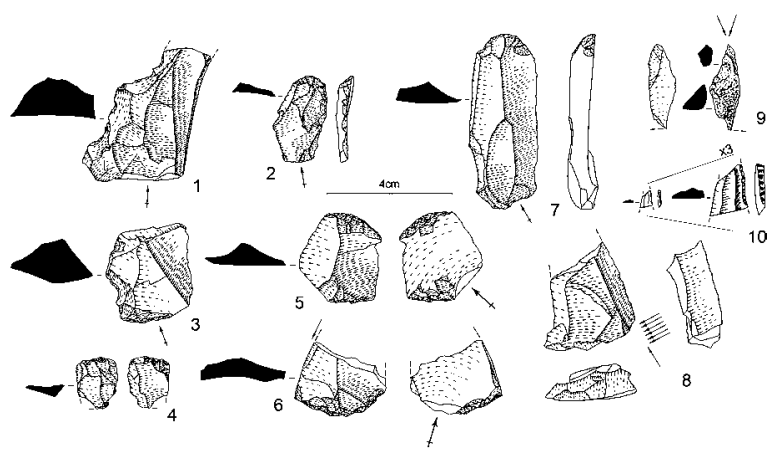

Fig. 5. Industria lítica del nivel Co.B.6 de Coímbre (Peñamellera Alta, Asturias). Junto con los elementos de sustrato $\left(n^{\circ} 1-6\right)$, buriles $\left(n^{\circ} 8-9\right)$ y raspadores $\left(n^{\circ} 7\right)$ en cuarcita, se aprecia el único elemento de dorso identificado ( $\left.n^{\circ} 10\right)$ en sílex). Elaboración propia.

(Fig. 5, Tab. 6). Los huesos con secciones menos densas, y por tanto con mejores cualidades como combustible, tienen el mayor grado de alteración. Tales indicios y evidencias apuntan al empleo del hueso como combustible en el nivel gravetiense de Coímbre B (Yravedra et al. 2016).

\subsection{Otros recursos}

La presencia de vértebras de Salmo trutta evidencia una explotación de los recursos piscícolas

\begin{tabular}{|l|c|c|c|c|}
\hline \multirow{2}{*}{ Nivel Co.B.6 } & Marrón & $\begin{array}{c}\text { Negro y/o } \\
\text { Blanco }\end{array}$ & & \\
\cline { 2 - 5 } & $\begin{array}{c}\text { \% hueso } \\
\text { quemado }\end{array}$ & $\begin{array}{c}\text { \% hueso } \\
\text { calcinado / } \\
\text { carbonizado }\end{array}$ & $\begin{array}{c}\text { NR } \\
\text { hueso } \\
\text { quemado }\end{array}$ & $\begin{array}{c}\text { NR } \\
\text { hueso no } \\
\text { quemado }\end{array}$ \\
\hline Bos / Bison & 58 & 42 & 31 & 16 \\
\hline Equus ferus & 75 & 25 & 4 & 2 \\
\hline Cervus elaphus & 8 & 92 & 12 & 12 \\
\hline Capra pyrenaica & 60 & 40 & 20 & 26 \\
\hline Indet. Talla Grande & 14 & 87 & 3.858 & 290 \\
\hline Indet. Talla Mediana & 32 & 68 & 68 & 305 \\
\hline Indet. Talla Pequeña & 11 & 89 & 644 & 14 \\
\hline Indeterminado & 22 & 78 & 7.351 & 151 \\
\hline Total & $\mathbf{1 9}$ & $\mathbf{8 1}$ & $\mathbf{1 1 . 9 8 8}$ & $\mathbf{8 1 6}$ \\
\hline
\end{tabular}

Tab. 6. Huesos afectados por alteraciones térmicas del nivel gravetiense de la cueva de Coímbre (Peñamellera Alta, Asturias) (modificado de Yravedra et al. 2016).

de los cercanos ríos de Besnes y Cares, aunque peor representada que la de la macrofauna. Por ahora en el nivel Co.B.6 no se ha documentado el consumo de moluscos marinos registrado en otros sitios cantábricos como La Garma A (Álvarez-Fernández 2007), pero sí objetos de adorno-colgantes a partir de conchas de gasterópodos marinos sin valor alimenticio. La recolección de los recursos litorales debió llevarse a cabo, como mínimo, a unos $20 \mathrm{~km}$ de distancia siguiendo el curso del

Trab. Prehist., 74, N. ${ }^{\circ}$ 1, enero-junio 2017, pp. 47-67, ISSN: 0082-5638

doi: $10.3989 /$ tp.2017.12183 
Cares hasta su desembocadura ${ }^{4}$, teniendo en cuenta la situación de la costa en este momento.

\section{LOS RESTOS ARQUEOLÓGICOS}

Se ha recuperado un número elevado de restos en el nivel Co.B.6 en una superficie ligeramente superior a los $3 \mathrm{~m}^{2}$, ya que el nivel se encuentra en parte erosionado por el nivel Co.B.5 en el cuadro J-27. Sobre todo son de industria lítica pero también hay escasos restos de industria ósea y algunos objetos de adorno-colgantes, que ayudan a completar la descripción del nivel y añaden un importante volumen de información a la caracterización del Gravetiense en la zona centro-occidental cantábrica. Recordemos que los hallazgos proceden de un área de excavación limitada y que las conclusiones derivadas de nuestro estudio no deben considerarse más allá de una hipótesis preliminar que ha de ser refutada con la ampliación de las excavaciones en un futuro.

\subsection{La industria lítica}

El conjunto lítico del nivel Co.B.6 está compuesto por 3.338 restos (Tab. 7), de los cuales tan solo $30(0,9 \%)$ son soportes retocados ${ }^{5}$. Esta distribución resulta muy desproporcionada en comparación con otros niveles de la misma cronología de la región cantábrica (Baldeón 1990; Ríos et al. 2011). Ello debe achacarse, en parte, al exhaustivo método de excavación llevado a cabo en Coímbre, que ha permitido recuperar todos los restos derivados de las actividades de talla: los microdesechos (restos inferiores a $10 \times 10$ $\mathrm{mm}$ ) y desechos de talla representan el 75,9\% del total, de los cuales los primeros son el $70,73 \%$. En primera instancia, el dato es un marcador de la intensa actividad de talla realizada en el yacimiento, además de un síntoma de la integridad del nivel carente de lavado o selección postdeposicional de materiales.

\footnotetext{
${ }^{4}$ Durante el Gravetiense seguramente habría que añadir unos $5 \mathrm{~km}$ más hasta la línea de costa.

${ }^{5}$ Sin los microdesechos subiría al 3,07\% ya que el conjunto quedaría en 977 efectivos.
}

\begin{tabular}{|c|c|c|c|c|c|c|c|c|c|}
\hline & \multirow{2}{*}{ Nivel Co.B.6 } & \multicolumn{5}{|c|}{$\begin{array}{l}\text { Materias primas de ámbito } \\
\text { local }\end{array}$} & \multirow[b]{2}{*}{$\mathrm{S}$} & \multirow[b]{2}{*}{ Ind. } & \\
\hline & & $\mathrm{C}$ & $\mathrm{Ch}$ & $\mathrm{L}$ & $\mathbf{R}$ & CR & & & \\
\hline \multirow{9}{*}{ 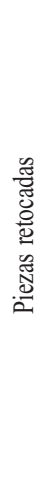 } & $\begin{array}{l}\text { Lámina } \\
\text { retocada }\end{array}$ & & & & & & 2 & & 2 \\
\hline & Lasca retocada & & & & 1 & & 1 & & 2 \\
\hline & Raedera & 1 & & & & & & & 1 \\
\hline & Raspador & 1 & & 1 & & & & & 2 \\
\hline & Denticulado & 6 & & & & & & & 6 \\
\hline & Punta de dorso & & & & & & 1 & & 1 \\
\hline & Truncadura & & & & & & 1 & & 1 \\
\hline & Buril & 5 & & & & & & & 5 \\
\hline & Écaillé & 6 & & & & 2 & 2 & & 10 \\
\hline \multicolumn{2}{|c|}{ Núcleos } & 6 & & & & & & & 6 \\
\hline \multicolumn{2}{|c|}{ Avivados núcleo } & 21 & & & 1 & & 2 & & 24 \\
\hline \multicolumn{2}{|c|}{ Lascas } & 503 & 3 & & 3 & 3 & 49 & 2 & 563 \\
\hline \multicolumn{2}{|c|}{ Láminas } & 65 & 1 & & 1 & & 3 & & 70 \\
\hline \multicolumn{2}{|c|}{ Laminitas } & 41 & & & 2 & & 21 & & 64 \\
\hline \multicolumn{2}{|c|}{ Golpes de buril } & 8 & & & & & 10 & & 18 \\
\hline \multicolumn{2}{|c|}{ Avivados útil } & 1 & & & & & & & 1 \\
\hline \multicolumn{2}{|c|}{ Desechos } & 156 & & & & 3 & 12 & 3 & 174 \\
\hline \multicolumn{2}{|c|}{ Microdesechos } & 2213 & & & & 24 & 124 & & 2361 \\
\hline \multicolumn{2}{|c|}{ Lítica no tallada } & 27 & & & & & & & 27 \\
\hline \multicolumn{2}{|c|}{ Total } & 3060 & 4 & 1 & 8 & 32 & 228 & 5 & 3338 \\
\hline
\end{tabular}

Tab. 7. Industria lítica del nivel Co.B.6 de la cueva de Coímbre (Peñamellera Alta, Asturias). C: Cuarcita; Ch: Chert; L: Lidita; R: Radiolarita; CR: Cristal de roca; S: Sílex; Ind: Indeterminado.

La materia prima mayoritaria es la cuarcita (91,7\% del total de la muestra), lo que no impide una presencia del $8,17 \%$ de rocas silíceas: chert, radiolarita, lidita, cristal de roca y sílex de distintas procedencias y orígenes. A efectos de cuantificar los elementos autóctonos y alóctonos, consideramos como parte del primer grupo las materias localizadas en el entorno inmediato de la cueva y cuya captación preferente ha podido tener lugar en los depósitos aluviales del río $\mathrm{Ca}$ res y sus afluentes (Álvarez-Alonso et al. 2013a). Estas rocas "locales" serían la cuarcita, el chert, la radiolarita, la lidita y el cristal de roca y suponen el 93\% del total del conjunto. En un segundo grupo englobamos las demás variedades criptocristalinas de la sílice. Algunas de ellas han podido 


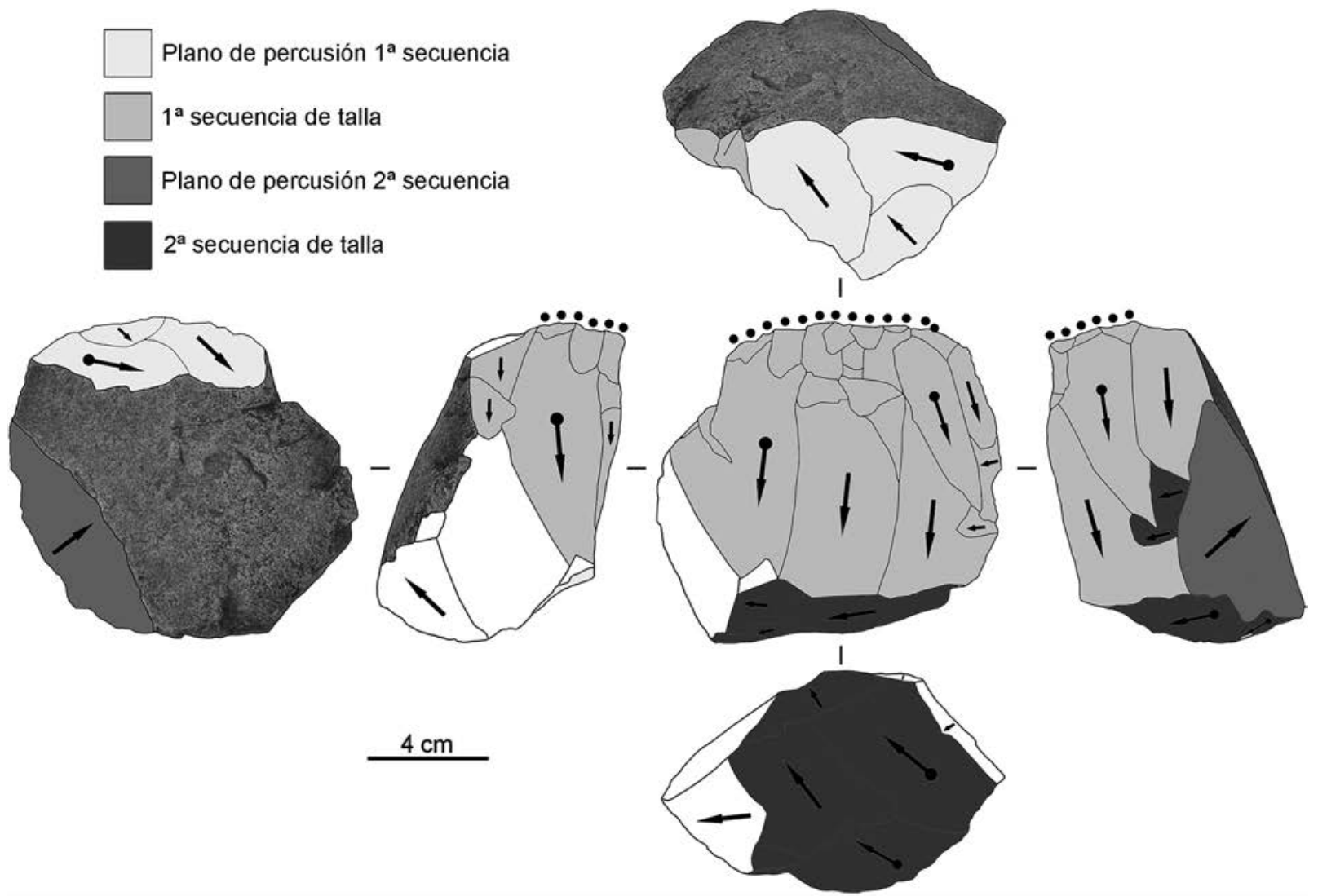

Fig. 6. Núcleo de cuarcita del nivel gravetiense Co.B.6 de la cueva de Coímbre (Peñamellera Alta, Asturias).

ser identificadas, aunque sabemos poco sobre su procedencia por la naturaleza y el estado de conservación de los restos. Únicamente han podido identificarse dos tipos: los sílex bioclásticos marinos de Piloña (Tarriño et al. 2013) y de Flysch, que podrían suponer como mínimo el 1,31\%. La posible presencia de sílex de Monte Picota/Piedramuelle ${ }^{6}$, Urbasa o Chalosse está pendiente de un análisis más detallado de estas piezas.

El aspecto general de la industria es "poco elaborado", especialmente en el grupo de los buriles (Fig. 6). La gran variedad de soportes existentes para la confección del utillaje retocado, una parte importante realizado mediante retoques muy someros, nos hacen interpretar esta industria como el resultado de requerimientos tecno-económicos

\footnotetext{
${ }^{6}$ Por razones de proximidad, es más probable que los indeterminados correspondan al tipo de Monte Picota, aunque por la imposibilidad de su diferenciación con garantías del de Piedramuelle hemos establecido una única categoría.
}

muy básicos, donde prima el componente de inmediatez en la fabricación y el uso. Destaca el reaprovechamiento de avivados de núcleo para la fabricación de utensilios, especialmente entre los denticulados, extremo puesto de relieve en otros conjuntos gravetienses de la región cantábrica (Calvo et al. 2013). También son dominantes los útiles denominados "de sustrato" con 10 écaillés o piezas astilladas y 6 piezas denticuladas, que suponen más de la mitad de los útiles registrados en el conjunto. Además, se han documentado 5 buriles y 2 raspadores. Subrayamos las pocas piezas de dorso rebajado, así como de los elementos tipológicos de valor diagnóstico para el Gravetiense.

Es notable que, a pesar del bajo número de buriles, haya 18 golpes de buril (entre ellos uno de écaillé-buril), considerando muy significativo que 9 de ellos y un golpe de écaillé-buril sean de sílex, ya que todos los buriles del conjunto se hicieron en cuarcita. Esto indica que se reavivaron 
buriles de sílex aportados desde el exterior y que, seguramente, habrían sido nuevamente acarreados fuera del yacimiento. Esta pauta de comportamiento resulta muy significativa e interesante a la hora de interpretar esta ocupación humana.

En definitiva, se trata de un reducido conjunto sin restos de atribuido valor crono-cultural para el contexto gravetiense como los elementos de dorso (laminitas y "Gravettes"/"microgravettes") o los buriles de "Noailles".

El total de restos líticos no retocados del nivel Co.B.6 es de 3.308 (Tab. 7), de los que 697 son productos brutos de talla (563 lascas, 70 láminas, 64 laminitas), 174 desechos de más de $1 \mathrm{~cm}^{2} \mathrm{y}$ 2.361 microdesechos inferiores a $10 \times 10 \mathrm{~mm}$ (93\% cuarcita; 5,25\% sílex). Completan el conjunto 43 tipos distintos de avivados, 6 núcleos y 27 herramientas de talla (percutores y fragmentos de percutores y yunques).

Las lascas son los productos dominantes $(80,7 \%)$. Las láminas (10\%) están realizadas principalmente en cuarcita y las laminitas $(9,2 \%)$ en un mayor porcentaje en sílex, en función del tamaño de los restos de rocas silíceas disponibles. Hemos analizado distintos componentes de carácter tecnológico para caracterizar las Cadenas Operativas líticas desarrolladas durante esta ocupación humana, su grado de integridad, su carácter y los patrones de aprovisionamiento, aprovechamiento y producción observados. Se ha tenido en cuenta el grado y tipo de corticalidad, las plataformas de percusión (tipos de talón y ángulos), el tipo de anversos de los productos de talla (su organización y dirección), el tipo de productos de avivado y los núcleos presentes. Tales elementos pueden ayudar a valorar y analizar estas Cadenas Operativas, puesto que el estudio tipológico de los útiles resulta limitado en este caso.

El grado de corticalidad de los restos de talla se ha estimado a partir de 762 efectivos. El 81\% carecen de córtex en su cara dorsal, el 13,22\% tienen restos corticales en su dorso y el $5,77 \%$ son productos de desbastado con un $100 \%$ de córtex en su cara dorsal. Esta proporción es muy reducida y sugiere que la mayoría de los núcleos ya contaban con un grado de preparación previo, que solo se transportan al yacimiento fragmentos de canto ya desbastados y preparados en origen o incluso que se están aprovechando materiales ya descortezados, presentes en la cueva. En este sentido cabe destacar que solo 26 (lascas de cuarcita $-n=7,4 \%$ ) de los 347 talones identificados tienen restos de córtex. Observando las lascas y las láminas, la proporción varía aún más: el $78 \%$ de las lascas no tiene córtex frente al $92,41 \%$ de las láminas. Todo apunta a que la cadena operativa laminar, más reducida y específica, presenta nada más que sus fases finales ya que tampoco se han recuperado núcleos de este tipo, ni de sílex. En la cuarcita varía mucho la localización y proporción del córtex en los soportes que conservan restos a lo largo de su cara dorsal y en las zonas laterales. Esto encaja con un patrón de talla donde la cadena operativa parece estar mucho más completa que en el sílex y se realiza en gran medida dentro del yacimiento, aunque las fases previas también parecen escasear. Por ejemplo el 84\% de las piezas de sílex no tienen restos de córtex y solo un 5,8\% son de decorticado primario. En resumen, se puede afirmar que difiere la gestión de las Cadenas Operativas de lascas y láminas (ya sean de sílex o cuarcita), así como la gestión del sílex y la cuarcita. Los formatos y soportes están mucho más preparados en la gestión del primero que en la de la segunda, y por lo tanto pertenecen a cadenas operativas que no han sido llevadas a cabo en sus etapas iniciales en el yacimiento.

La preparación de las superficies de talla se identifica en 347 talones de distintos soportes. Los lisos $(76,6 \%)$ son mayoritarios en lascas y láminas. Los talones facetados y diedros son el 13,5\%. Los ángulos de percusión no son excesivamente significativos, pero la mayoría de los 322 estudiados en lascas y láminas se sitúan entre $101^{\circ}$ y $110^{\circ}\left(74,5 \%\right.$ por encima de $\left.101^{\circ}\right)$. Esta amplia variabilidad seguramente refleja un bajo requerimiento técnico en la obtención del elemento mayoritario: las lascas de cuarcita.

Las caras dorsales identificadas en todos los soportes brutos de talla muestran que, entre las lascas, dominan los esquemas unipolares $(68,5 \%)$, seguidos de los unipolares+perpendiculares $(10,6 \%)$. Los tipos bipolares $(8,8 \%)$ o centrípetos $(2 \%)$ son poco significativos. En las láminas, son aún más mayoritarios los esquemas unipolares $(89,2 \%)$, muy lejos de los bipolares $(8,5 \%)$ o los unipolares+perpendiculares $(2,3 \%)$. Esto último parece reflejar una mayor uniformidad en los sistemas de explotación laminar y una mayor variabilidad en relación a los empleados para la obtención de lascas, menos estandarizados. En cualquier caso, se aprecia una importante tenden- 
cia hacia esquemas de explotación relativamente sencillos de tipo unipolar.

La información anterior debe ser combinada con los núcleos procedentes del conjunto, pero en este caso se trata de una muestra pequeña en cuarcita (Fig. 6): cinco núcleos con mayor o menor grado de jerarquización y morfologías prismáticas - o tendentes a ellas - y un fragmento de núcleo centrípeto de lascas. Tres de los primeros siguen patrones de explotación muy similares: prismáticos con dos planos de percusión y lascado ortogonales para la producción de lascas y, fundamentalmente, lascas laminares. Otros dos núcleos parecen seguir este mismo patrón, aunque con escaso aprovechamiento.

Hay 24 productos de avivado y acondicionamiento: 21 de cuarcita y 3 de sílex. Entre los primeros aparecen todos los elementos de preparación y mantenimiento de la talla: 6 láminas cresta, 8 cornisas, 6 flancos y 1 tableta. Es decir, como anteriormente, se documentan todas las fases de producción, desde el desbastado hasta el reavivado y la obtención de soportes brutos.

De todo lo apuntado se desprende que es un conjunto lítico con pocos requerimientos técnicos, orientado principalmente a la obtención de lascas de cuarcita, lo cual conlleva un grado de inmediatez elevado en el desarrollo de esta cadena operativa. Cadenas operativas, como la laminar (fundamentalmente en cuarcita) han sido elaboradas en el yacimiento en un grado menor que la anterior. La cadena operativa del sílex es casi inexistente y se limita con seguridad a la presencia de elementos foráneos, previamente elaborados que, simplemente, han sido reavivados en el yacimiento, faltando actividad de talla para la obtención de soportes en esta materia prima. En general serían elementos de un utillaje portátil que evidencia, junto con los datos aportados por la cuarcita, el carácter transitorio y oportunista de la ocupación humana del nivel Co.B.6.

\subsection{La industria ósea}

La industria ósea recuperada es escasa y poco significativa. Consiste en 12 fragmentos, de los cuales 9 corresponden a una parte central o indeterminable de azagayas/varillas menores de $2 \mathrm{~cm}$ de longitud; 1 pequeña costilla con marcas y 2 diáfisis usadas como útil con marcas de uso y abrasión en sus aristas. En total estimamos un NMI de 11 piezas. Siete de los restos del cuadro J-26 están completamente quemados con algunas evidencias de calcinación como las de la mayoría de la colección faunística. Proceden de una posible área de combustión identificada por el estudio de la fauna y las evidencias arqueológicas identificadas. Pensamos que la presencia de estas piezas óseas incompletas pudiera corresponder a una fase posterior a su completa amortización, cuando solo los pequeños restos ya inservibles han sido abandonados en el yacimiento. Destacamos la falta de fragmentos distales y apuntados, potencialmente reaprovechables. Carecemos de paralelos, dado que no hay muchas evidencias de industria ósea en la bibliografía sobre la región cantábrica y las piezas halladas en Cueto de la Mina o Isturitz (Bernaldo de Quirós 1982; Martínez 201577) no son equiparables con las de Coímbre.

\subsection{Objetos de adorno}

En el nivel Co.B.6 de Coímbre se han documentado tres objetos de adorno-colgantes bastante degradados, elaborados en conchas de Littorina obtusata, así como otros fragmentos de conchas de la misma especie, recogidas en la costa cantábrica.

Se conocen 155 objetos de adorno- colgantes en más de una docena de sitios gravetienses cantábricos. Como materia prima se recurre a las conchas recientes (más del $80 \%$ ) más que a los dientes y el hueso. Predominan las conchas de gasterópodos, y en mucha menor medida, de escafópodos y bivalvos. L. obtusata es la especie más abundante (ca. 75\%) entre los gasterópodos. Otras especies identificadas en los sitios gravetienses cantábricos son Trivia sp., Littorina littorea, Littorina saxatilis, Nassarius reticulatus, Nucella lapillus y Luria lurida, en su mayoría caracoles sin valor alimenticio (salvo L. littorea). Las huellas de erosión en las conchas provocadas por el agua del mar y la arena indican que estaban ya vacías cuando se recogieron en las playas. Littorina obtusata también está presente en Fuente del Salín (nivel 2), Cueva Morín (nivel 4) y La Garma A (nivel E) (Álvarez-Fernández 2006; Álvarez-Fernández y Avezuela 2012).

${ }^{7}$ Véase n. 1.

Trab. Prehist., 74, N. ${ }^{\circ}$ 1, enero-junio 2017, pp. 47-67, ISSN: 0082-5638

doi: $10.3989 /$ tp.2017.12183 


\section{DISCUSIÓN}

La situación de Coímbre y las características de los restos recuperados indican que se trata de un yacimiento eminentemente de interior, sin evidencias de explotación de recursos litorales con fines bromatológicos, aunque resulta manifiesto el contacto con la cercana costa. El modelo económico del nivel gravetiense se centra fundamentalmente en la caza de presas de gran porte, cuyo nicho ecológico preferente era necesariamente el entorno inmediato de la cueva. Sin olvidar que estamos ante una excavación reducida en una cueva de grandes dimensiones, la ocupación gravetiense en Coímbre B parece bastante atípica en el contexto regional. Esto se debe a la escasez de paralelos y a un registro que, al margen de su acotada cronología, resulta bastante difícil de clasificar y contextualizar en el marco arqueológico conocido para el Gravetiense cantábrico (Calvo et al. 2016). La disponibilidad de materias primas líticas ocasiona la primera divergencia tecnológica y tipológica entre las industrias del sector más occidental de la región donde se localiza la cueva y los yacimientos de Cantabria y, sobre todo, del País Vasco. A su vez, la función logística y carácter posiblemente eventual de la ocupación en Coímbre originan unas características que ya hemos ido desgranando, que trataremos de interpretar convenientemente en las líneas que siguen.

En primer lugar, los escasos paralelos cronológicos existentes para el nivel Co.B.6 no encuentran muchos reflejos en la industria lítica. La colección lítica de ese nivel difiere notablemente del resto de la de los niveles gravetienses de su entorno más inmediato (Llonín, Cueto de la Mina), o incluso de las evidencias más occidentales de presencia gravetiense en la región cantábrica (abrigo de La Viña). Ya se ha indicado la gran divergencia en la representación de la cuarcita y el sílex. A pesar de que en Asturias también predomina un aprovisionamiento estrictamente local $^{8}$, los porcentajes de cuarcita y sílex en Co.B.6 (91,7\% y 7,21\% respectivamente) resultan únicos. La cuarcita nunca representa más del $63 \%$ en La Viña IX y el sílex nunca baja del 33\% en Cueto de la Mina

\footnotetext{
${ }^{8}$ En este caso, se consideran materias primas locales a la cuarcita, la radiolarita y el chert, accesibles en el entorno inmediato de Coímbre.
}

VII (Martínez 2015; Calvo et al. 2016). Parece razonable atribuir estas diferencias a la proximidad de algunos yacimientos, como La Viña, a afloramientos explotables de sílex. Sin embargo Llonín, yacimiento situado a escasos kilómetros de Coímbre y con idéntica accesibilidad a los mismos recursos, ofrece en su nivel $\mathrm{V}$ los datos más extremos en este sentido: en torno al $49 \%$ de cuarcita y al 46\% de sílex ${ }^{10}$ (Martínez 2015 ${ }^{11}$; Calvo et al. 2016). Ello parece abundar en nuestro planteamiento de la especificidad de la ocupación en Coímbre, tal vez estrictamente logística y asociada a una funcionalidad muy concreta, de carácter bastante puntual y esporádico.

La singularidad del nivel Co.B.6 también resalta en relación con las características tecno-tipológicas del conjunto lítico. El exiguo porcentaje de elementos retocados no es un hecho aislado. En los yacimientos más cercanos como Sopeña (los niveles I-XI), Llonín (nivel V) y Cueto de la Mina (nivel VII), los útiles retocados también son escasos (totales 69, 29 y 65 respectivamente), aunque sus porcentajes respecto al resto de la industria no son tan reducidos. Recordemos la falta en el nivel Co.B.6 de elementos diagnósticos, como los buriles de "Noailles", bien representados en toda la secuencia gravetiense de La Viña, o las puntas tipo "La Gravette" o "Microgravette", relevantes en Cueto de la Mina VII y Llonín V y, en menor medida, en los niveles VII y VIII de La Viña (. Los elementos de dorso, abundantes en casi todos estos niveles, están prácticamente ausentes en el nivel Co.B.6 de Coímbre. Por el contrario, los ecaillés y denticulados, los dos principales grupos tipológicos de este nivel, son elementos de sustrato muy frecuentes en otros conjuntos. Los ecaillés son los útiles mejor representados en Cueto de la Mina VII y los denticulados en los niveles VII, VIII y IX de La Viña (Rasilla y Santamaría 2006; Calvo et al. 2016; Martínez $2015^{12}$ ). La dicotomía en la gestión de la cuarcita y el sílex también se observa en el resto de conjuntos gravetienses (Martínez 2015 ${ }^{13}$; Calvo et al. 2016). En Coímbre destaca la fabricación preferente de ecaillés y denticulados en cuarcita.

\footnotetext{
9 Véase n. 1.

${ }^{10} \mathrm{Al}$ que en este caso se ha sumado la radiolarita.

${ }_{11}$ Véase n. 1.

12 Véase n. 1.

13 Véase n. 1.
} 
En sílex se elabora la única punta de dorso del conjunto, además de dos láminas retocadas. Se trata, por tanto, de un conjunto muy especializado y que muestra un grado de inmediatez elevado en la gestión, uso y amortización de los recursos.

La talla de tipo ortogonal sobre núcleos prismáticos documentada en el nivel Co.B.6 es rara en el conjunto del Cantábrico, donde predominan esquemas estrictamente unipolares sobre los prismáticos, piramidales, carenados, etc. sin olvidar la aparición esporádica de la talla bipolar (e.g. Cava et al. 2009; ${ }^{14}$; Aguirre 2014; Bradtmöller 2014; Martínez $2015^{15}$ ). Esta peculiaridad puede ser debida al condicionante impuesto por la cuarcita, la materia prima de empleo preferente.

Establecer paralelos en un marco regional más amplio es aún más difícil. Además del escaso número de útiles retocados del nivel Co.B.6, hay una importante dualidad territorial en el Cantábrico en relación a la captación de materias primas y a su explotación tecnológica. Es francamente complicado comparar una colección elaborada en su práctica totalidad en cuarcita con otras basadas en una materia prima tan distinta como el sílex, caso de las de los yacimientos del País Vasco y algunos de Cantabria, en especial Cueva Morín. Asumiendo esta gran divergencia de base, tampoco se encuentran paralelos con la industria del nivel Co.B.6. Como comentamos para Asturias, aquí están prácticamente ausentes las laminitas o puntas de dorso, importantes en Altamira 8, Morín 4, Mugarduia Sur, Aldatxarren, Ametzagaina Este, Alkerdi 2 o Irikaitz II, entre otros conjuntos (Heras et al. 2012b; Bradtmöller 2015; Cava 2014; Sáenz de Buruaga 2008; Calvo et al. 2013; Arrizabalaga et al. 2014; Cava et al. 2009; Arrizabalaga e Iriarte 2011). La ausencia de las puntas de "La Gravette" o "Microgravettes", presentes también en varios yacimientos cántabros y vascos como Altamira 8, Morín 4, Mugarduia Sur o Bolinkoba VI/F, ya se dijo anteriormente (Bradtmöller 2014). Además, la aparición de los buriles, uno de los grupos tipológicos dominantes en el sector oriental de la cornisa cantábrica, es testimonial y en ningún caso bajo formas de atribuido

\footnotetext{
14 Peña, P. de la 2012: Sobre la unidad tecnológica del Gravetiense en la Península Ibérica: implicaciones para el conocimiento del Paleolítico Superior inicial. Tesis doctoral inédita. Universidad Complutense de Madrid.

${ }^{15}$ Véase $\mathrm{n} .1$
}

valor cronológico. Ello aleja los buriles de Co.B.6 de conjuntos importantes como los de Antoliñako Koba Lab/Sab, Bolinkoba VI/F, Amalda VI y V, Ametzagaina E o Aitzbitarte Va y IV, en los cuales el buril de "Noailles" aparece en un número importante (Baldeón 1990; Ríos et al. 2011; Aguirre 2013). Los ecaillés y, sobre todo, los denticulados, habitualmente poco atendidos en la bibliografía, son elementos cuantitativamente importantes en muchos conjuntos. Es el caso de los ecaillés en los niveles Va y IV de Aitzbitarte III o Alkerdi 2 y de los denticulados en Antoliñako Koba Lmbk sup/Sabk y Lab/Sab, Bolinkoba VI/F, Amalda VI y V o Mugarduia Sur (Baldeón 1990; Aguirre 2013; Bradtmöller 2014; Cava 2014).

Si en lo referente al conjunto lítico, Coímbre parece un caso bastante atípico y con pocos paralelos, no menos interesante resultan las peculiaridades de su registro faunístico. En este nivel, y a diferencia de lo que sucede en toda la secuencia magdaleniense posterior de Coímbre B (ÁlvarezAlonso et al. 2016), las especies de explotación preferente no son las potencialmente dominantes en el entorno inmediato: cabras o rebecos. Se opta, en cambio, por animales de talla grande que no serían los más habituales a tenor de las características del medio físico circundante. Esto de por sí indica un patrón específico, alejado de la especialización territorial implícita en la explotación del recurso más abundante y típico del entorno y cercano a una especialización o preferencia cinegética en especies concretas, no condicionada por las características del medio.

La selección de animales de talla grande, unida al uso del hueso como combustible, podría relacionarse hipotéticamente con una doble finalidad funcional de los recursos óseos. Esta práctica, puesta en evidencia en el nivel Co.B.6, podría dotar a esta ocupación de una gran peculiaridad con respecto a otras contemporáneas, si este comportamiento fuera fruto de una estrategia de ocupación orientada a obtener la máxima eficiencia en el aprovechamiento de los recursos cinegéticos disponibles. Las características frías y húmedas del momento al que se corresponde el nivel estudiado con un paisaje circundante de espacios abiertos con escasa vegetación arbórea limitan los combustibles potenciales a determinadas especies arbustivas. En ese contexto, emplear el hueso como combustible podría haber sido una estrategia de optimización de los recursos dispo-

Trab. Prehist., 74, N. ${ }^{\circ}$ 1, enero-junio 2017, pp. 47-67, ISSN: 0082-5638

doi: $10.3989 /$ tp.2017.12183 
nibles, en un marco de inmediatez elevada en la captación y uso de los mismos. Este hecho podría ser una evidencia más para apuntar una ocupación no estratégica ni estable, sino más bien puntual y ligada a movimientos de grupos humanos desde el sector oriental cantábrico con más alta ocupación hacia el oriental con menores evidencias gravetienses, y potencialmente con menor presencia humana.

La utilización del hueso como combustible en el nivel analizado de Coímbre es una de las primeras evidencias de esta práctica en el Gravetiense peninsular. Se suma a las del Esquilleu, correspondiente al Paleolítico medio (Yravedra et al. 2005; Yravedra y Uzquiano 2013) y a las de los niveles auriñacienses de Labeko Koba (Yravedra et al. 2005), el Gravetiense de Aitzbitarte III (Altuna y Mariezkurrena 2011) y Gargas (Foucher et al. 2012; Vercoutère et al. 2013). Estos cinco yacimientos contienen las únicas evidencias de este tipo de comportamiento en el Paleolítico medio y superior de la península ibérica y sus proximidades (Yravedra et al. 2016).

Coímbre abre también la puerta a otra interpretación del supuesto vacío de ocupaciones gravetienses en el extremo occidental cantábrico, basado en la ausencia de los clásicos "fósiles directores" y en la industria lítica fundamentalmente en cuarcita dominada por útiles de sustrato con aspecto arcaico. En las cuevas asturianas son numerosas las excavaciones antiguas y niveles registrados previos al Solutrense, que han sido asignadas tradicionalmente al Auriñaciense, ante la falta de dataciones y otros elementos diagnósticos. Bajo nuestro punto de vista, apoyado fundamentalmente en la cronología, el nivel Co.B.6 de Coímbre ofrece un nuevo panorama para interpretar la variedad y dispersión del Gravetiense en el extremo occidental cantábrico.

El centro y oriente de la región cantábrica, sobre todo hacia el foco pirenaico, se muestra como uno de los lugares con más alta ocupación y presencia humana durante dicho periodo, presencia que hacia el occidente parece la excepción y está localizada en núcleos muy concretos, como el valle del Nalón, que nunca llegan a la gran densidad de yacimientos orientales como Aitzbitarte III o Isturitz.

Parece que esos movimientos se producen en momentos ya avanzados del Gravetiense, a tenor de la cronología del Gravetiense occidental más reciente que la de las secuencias amplias del ámbito pirenaico. Su objetivo sería penetrar en nuevos territorios o avanzar hacia enclaves estacionales, recurrentes y estratégicos como podría ser el abrigo de La Viña en el valle del Nalón. Esa ruta oriente-occidente queda patente en un eje cercano al litoral, y por lo tanto a territorios más abiertos, mejor conectados y con materias primas silíceas, definido por numerosos yacimientos gravetienses que van desde enclaves orientales como Ametzagaina o Irikaitz hasta Cueto de la Mina. Otra ruta alternativa por el interior parece penetrar siguiendo el curso del Cares-Güeña hasta el centro de la región. Yacimientos como Fuente del Salín, Llonín, Coímbre o Sopeña pueden considerarse enclaves a favor de la presencia humana gravetiense en este itinerario. A su vez, en el nivel Co.B.6, el hallazgo de sílex de Piloña y del Flysch establecen una clara conexión entre el área oriental y el interior más occidental de la región asturiana, a medio camino entre las cuencas del Nalón y del Cares.

El valle del Cares podría representar una vía de paso, con un medio físico fundamentalmente montañoso y escarpado, donde las estrategias de subsistencia basadas en la caza de grandes ungulados tendrían menos éxito que en lugares, como el valle del Nalón y la cuenca central asturiana o la zona litoral. No se puede descartar que este corredor interior sea solo una vía de paso o comunicación hacia territorios más occidentales. En este contexto y con esta hipótesis como vía de trabajo, la presencia humana gravetiense documentada en Coímbre, encuentra una explicación convincente y una clara justificación, como un posible enclave puntual en un contexto de movilidad desde el oriente al occidente de la región cantábrica.

\section{CONCLUSIONES}

Las dataciones de Coímbre abundan en la idea que parecen esbozar los escasos datos cronológicos disponibles para el Gravetiense en Asturias: que la ocupación de este sector occidental de la cornisa cantábrica fue aparentemente más intensa a partir del $25 \mathrm{ka} \mathrm{BP}$, en torno a lo que podría llamarse la "segunda mitad" del desarrollo regional. Desconocemos las razones para ello, aunque podemos intuir y plantear una mayor articulación 
del territorio cantábrico hacia esta etapa. Es la hipótesis que hemos propuesto basada en una movilidad creciente de la población hacia el occidente. Sin embargo la ausencia de contextos bien analizados y datados para momentos anteriores y contemporáneos en el extremo occidental cantábrico aconsejan precaución.

La industria lítica y la fauna del nivel Co.B.6 son exponentes de una ocupación humana donde parece haber un grado elevado de inmediatez en la captación de recursos líticos y faunísticos, así como unos requerimientos técnicos no excesivamente complejos. Esto encajaría en una ocupación alejada de un contexto de hábitat residencial o prolongado y más asociada con uno transitorio con finalidad logística. En resumen, creemos que la ocupación gravetiense de Coímbre podría ser coherente con un esquema de movilidad de un grupo de cazadores-recolectores que emplean la cueva como un refugio temporal y estratégico en relación con yacimientos cercanos de cronologías similares pero diferentes características, en el marco de desplazamientos a larga distancia.

\section{AGRADECIMIENTOS}

A los dos evaluadores anónimos sus comentarios que nos han ayudado a mejorar el resultado final.

\section{BIBLIOGRAFÍA}

Aguirre, M. 2013: “Ocupaciones gravetienses de Antoliñako Koba: aproximación preliminar a su estratigrafía, cronología e industrias". En C. de las Heras, J. A. Lasheras, A. Arrizabalaga y M. de la Rasilla (eds.): Pensando el Gravetiense: nuevos datos para la región cantábrica en su contexto peninsular y pirenaico. Monografías de Altamira 23, Museo Nacional y Centro de Investigación de Altamira. Madrid: 229-242.

Aguirre, M. 2014: "Caracterización tecnológica de la industria lítica de Mugarduia sur (Urbasa, Navarra)". En I. Barandiarán, A. Cava y M. Aguirre (eds.): El taller de sílex de Mugarduia Sur: una ocupación de Urbasa (Navarra) durante el Gravetiense. Servicio Editorial de la Universidad del País Vasco. Leioa: 401-520.
Altuna, J. 1992: "Dataciones de radiocarbono para el Perigordiense Superior del País Vasco". Munibe 43: 31-32.

Altuna, J. y Mariezkurrena, K. 2011: "Estudio de los macromamíferos del yacimiento de Aitzbitarte III (Excavación de la entrada)". En J. Altuna, K. Mariezkurrena y J. Ríos (eds.): Ocupaciones humanas en Aitzbitarte III (País Vasco) 33600-18400 BP (Zona de entrada a la cueva). EKOB 5. Euskal Kultura Ondare Bilduma/Colección de Patrimonio Cultural Vasco, Gobierno Vasco. Vitoria-Gasteiz: 395-480.

Altuna, J.; Mariezkurrena, K. y Ríos, J. 2011: Ocupaciones humanas en Aitzbitarte III (País Vasco) 33600-18400 BP (Zona de entrada a la cueva). EKOB 5. Euskal Kultura Ondare Bilduma/Colección de Patrimonio Cultural Vasco, Gobierno Vasco. Vitoria-Gasteiz

Álvarez-Alonso, D.; Andrés Herrero, M. de y Rojo, J. 2013a: "La captación de materias primas líticas durante el Paleolítico en el oriente de Asturias, y su caracterización litológica en la cuenca de los ríos Sella y Cares (Asturias, España)". En R. Baena, J. J. Fernández e I. Guerrero (eds.): El Cuaternario Ibérico: investigación en el siglo XXI. VIII Reunión de Cuaternario Ibérico (Sevilla-La Rinconada 2013): 296-299. Sevilla.

Álvarez-Alonso, D.; Arrizabalaga A.; Jordá Pardo J. F. e Yravedra J. 2011: "La secuencia estratigráfica magdaleniense de la cueva de Coímbre (Peñamellera Alta, Asturias, España)". Férvedes 7: 57-64.

Álvarez-Alonso, D. e Yravedra, J. (eds.) (en prensa): La cueva de Coímbre (Peñamellera Alta, Asturias). Ocupaciones humanas en el valle del Cares durante el Paleolítico Superior. Ed. Fundación María Cristina Masaveu Peterson.

Álvarez-Alonso, D.; Yravedra, J.; Andrés Herrero, M. de.; Arrizabalaga, A.; García Díez, M.; Garrido, D. y Jordá Pardo, J. F. 2014: "La cueva de Coímbre (Asturias, España): artistas y cazadores durante el Magdaleniense en la Región Cantábrica". En M. ${ }^{a}$ S. Corchón y M. Menéndez Fernández (eds.): Cien Años de arte rupestre paleolítico. Centenario del descubrimiento de la cueva de la Peña de Candamo (1914-2014). Acta salmanticensia. Estudios históricos y geográficos 106, Universidad de Salamanca. Salamanca: 101-108

Álvarez-Alonso, D.; Yravedra J.; Arrizabalaga, A. y Jordá Pardo J. F. 2013b: "Excavaciones arqueológica en la cueva de Coímbre (Besnes, Peñamellera Alta). Campañas 2008-2012". Excavaciones Arqueológicas en Asturias 2007-2012: 109-120.

Álvarez-Alonso, D.; Yravedra J.; Arrizabalaga, A.; Jordá Pardo J. F. y Heredia, N. 2009: "La cueva de Coímbre (Peñamellera Alta, Asturias, España): su yacimiento arqueológico y su santuario rupestre. Un estado de la cuestión en 2008". Munibe 60: 139-155.

Trab. Prehist., 74, N. ${ }^{\circ}$ 1, enero-junio 2017, pp. 47-67, ISSN: 0082-5638

doi: $10.3989 /$ tp.2017.12183 
Álvarez-Alonso, D.; Yravedra, J.; Jordá Pardo, J. F. y Arrizabalaga, A. 2016: "The Magdalenian sequence at Coímbre cave (Asturias, Northern Iberian Peninsule). Adaptative strategies of hunter-gatherer groups in montane environments". Quaternary International 402:100-111.

Álvarez-Fernández, E. 2006: Los objetos de adornocolgantes del Paleolítico Superior y del Mesolítico en la cornisa cantábrica y en el valle del Ebro: un visión europea. Colección Vítor 195, Universidad de Salamanca. Salamanca.

Álvarez-Fernández, E. 2007: “La explotación de los moluscos marinos en la Cornisa Cantábrica durante el Gravetiense: primeros datos de los niveles E y F de La Garma A (Omoño, Cantabria)". Zephyrus LX: 43-58.

Álvarez-Fernández, E. y Avezuela Aristu, B. 2012: "Los objetos de adorno-colgantes durante el Gravetiense en el SW de Europa". En C. de las Heras, J. A. Lasheras, A. Arrizabalaga y M. de la Rasilla (eds.): Pensando el Gravetiense: nuevos datos para la región cantábrica en su contexto peninsular y pirenaico. Monografías de Altamira 23, Museo Nacional y Centro de Investigación de Altamira. Madrid: 593-603.

Andrés-Herrero, M.; Álvarez-Alonso, D.; Arrizabalaga, A.; Becker, D.; Weniger, Ch.-G. e Yravedra, J. en prensa: "Site catchment analysis and human behaviour during the Upper Palaeolithic in the Cantabrian Region: Coímbre cave (Asturias, Spain) as case study". Raw materials explotaition in Prehistory: sourcing, processing and distribution. Cambridge Scholars Publishing.

Arrizabalaga, A. 1998: "La gestación de la Prehistoria europea: el ejemplo del Paleolítico superior inicial en el sudoeste francés". En Antoine d'Abbadie 1897-1997. Congrès International. (Hendaye 1997): 95-116. Donostia y Bilbao.

Arrizabalaga, A.; Calvo, A.; Elorrieta, I.; Tapia, J. y Tarriño, A. 2014: "Where to and what for? Mobility patterns and the management of lithic resources by Gravettian hunter-gatherers in the Western Pyrenees". Journal of Anthropological Research 70: 233-261.

Arrizabalaga, A. e Iriarte, M. J. 2011: "Lower and Upper Palaeolithic settlements in Irikaitz (Zestoa, Basque Country, Spain). Deconstruction of a Pleistocene archaeological site in the eastern Cantabrian Range". Cuaternario y Geomorfología 25(1-2): 105-120.

Arrizabalaga, A. y Peña, P. de la 2013: “El registro de la industria lítica como base para una organización del Gravetiense cantábrico". En C. de las Heras, J. A. Lasheras, A. Arrizabalaga y M. de la Rasilla (eds.): Pensando el Gravetiense: nuevos datos para la región cantábrica en su contexto peninsular y pirenaico. Monografías de Altamira 23, Museo Nacional y Centro de Investigación de Altamira. Madrid: 347-368.
Aseguinolaza, C.; Gómez, D.; Lizaur, X.; Montserrat, G.; Morante, G.; Salaverria, M. R. y Uribe, P. M. 1989. Vegetación de la Comunidad Autónoma del País Vasco. Ed. Gobierno Vasco. Vitoria.

Baldeón, A. 1990: "La industria lítica de los niveles paleolíticos". En J. Altuna, A. Baldeón y K. Mariezkurrena (eds.): La cueva de Amalda (Zestoa, País Vasco). Ocupaciones Paleolíticas y Pospaleolíticas. Fundación José Miguel de Barandiarán. San Sebastián: 63-115.

Bernaldo de Quirós, F. 1982: Los inicios del Paleolítico Superior Cantábrico. Monografías del Museo y Centro de Investigación de Altamira 8, Ministerio de Cultura. Santander.

Bernaldo de Quirós, F.; Castaños, P.; Maíllo Fernández, J. M. y Neira, A. 2013: "El Gravetiense de la cueva de El Castillo. Nuevos datos". En C. de las Heras, J. A. Lasheras, A. Arrizabalaga y M. de la Rasilla (eds.): Pensando el Gravetiense: nuevos datos para la región cantábrica en su contexto peninsular y pirenaico. Monografías de Altamira 23, Museo Nacional y Centro de Investigación de Altamira. Madrid: 264-275.

Björck, S.; Walker, M. J. C.; Cwynar, L. C.; Johnsen, S.; Knudsen, K.L.; Lowe, J. J.; Wohlfarth, B. y Intimate-Members, 1998: "An Event Stratigraphy for the Last termination in the North Atlantic Region Based on the Greenland Ice-core Record: a Proposal by the INTIMATE Group". Journal of Quaternary Science 13: 283-292.

Bradtmöller, M. 2014: Höhlenlager des Gravettien: Muster jungpaläolithischer Höhlennutzung am Beispiel des Gravettien Nordspaniens. Schriften zur Urund Frühgeschichte 1, Verlag Dr. Kova. Hamburgo.

Bradtmöller, M. 2015: "The Gravettian occupation of Level 4 at Cueva Morín (Cantabrian Region) and its regional context". Munibe 66: 23-52.

Calvo, A.; Bradtmöller. M.; Martínez, L. y Arrizabalaga, A. 2016: "Lithic cultural variability duringthe Gravettian in the Cantabrian Region and Western Pyrenees: State of the art". Quaternary International 406(A): 25-43.

Calvo, A.; Tapia, J.; Arrizabalaga, A. e Iriarte-Chiapusso, M. J. 2013: "El yacimiento de Ametzagaina (Donostia, País Vasco). Un campamento gravetiense al aire libre en el Cantábrico". En C. de las Heras, J. A. Lasheras, A. Arrizabalaga y M. de la Rasilla (eds.): Pensando el Gravetiense: nuevos datos para la región cantábrica en su contexto peninsular y pirenaico. Monografías de Altamira 23, Museo Nacional y Centro de Investigación de Altamira. Madrid: 243-254.

Cava, A. 2014: "La industria lítica de Mugarduia sur: objetos retocados de la excavación". En I. Barandiarán, A. Cava y M. Aguirre (eds.): El taller de sílex de Mugarduia Sur: una ocupación de Urbasa (Navarra) durante el Gravetiense. Servicio Editorial de la Universidad del País Vasco. Leioa: 109-265. 
Cava, A.; Elorrieta, I. y Barandiarán, I. 2009: “El Gravetiense de la cueva de Alkerdi (Urdax, Navarra): análisis y contexto de su industria lítica". Munibe 60: 51-80.

Fortea, J. 1992: “Abrigo de la Viña. Informe de las campañas de 1987 a 1990”. Excavaciones arqueológicas en Asturias 1987-90. Servicio de Publicaciones del Principado de Asturias. Oviedo: 19-28.

Fortea, J.; Rasilla, M. de la y Rodríguez Otero, V. 1995: "La cueva de Llonín (Llonín, Peñamellera Alta). Campañas de 1991 a 1994". Excavaciones Arqueológicas en Asturias 1991-1994. Consejería de Cultura, Principado de Asturias: 33-43.

Foucher, P. 2013: "Synthèse chrono-culturelle sur le Gravettien des Pyrénées: constant et réflexions sur la stabilité régionale des traditionr techniques". En C. de las Heras, J. A. Lasheras, A. Arrizabalaga y M. de la Rasilla (eds.): Pensando el Gravetiense: nuevos datos para la región cantábrica en su contexto peninsular y pirenaico. Monografías de Altamira 23, Museo Nacional y Centro de Investigación de Altamira. Madrid: 142-159.

Foucher, P. ; San Juan-Foucher C. ; Vercoutère C.; Ferrier C. 2012: "La grotte de Gargas (Hautes-Pyrénées, France): l'apport du contexte archéologique à l'interprétation de l'art pariétal'. En J. Clottes (ed.): L'art pléistocène dans le monde / Pleistocene art of the world / Arte pleistoceno en el mundo. Actes du Congrès IFRAO (Tarascon-sur-Ariège 2010). N spécial de Préhistoire, Art et Sociétés, Bulletin de la Société Préhistorique Ariège-Pyrénées LXV-LXVI, 2010-2011: 52-53 y CD: 209-225.

Heras, C. de las; Lasheras, J. A.; Arrizabalaga, A. y Rasilla, M. de la (eds.) 2012a: Pensando el Gravetiense: nuevos datos para la región cantábrica en su contexto peninsular y pirenaico. Monografías de Altamira 23, Museo Nacional y Centro de Investigación de Altamira. Madrid (ed. español, inglés, francés).

Heras, C. de las; Montes, R. y Lasheras, J. A. 2012b: "Altamira: nivel gravetiense y cronología desu arte rupestre". En C. de las Heras, J. A. Lasheras, A. Arrizabalaga y M. de la Rasilla (eds.): Pensando el Gravetiense: nuevos datos para la región cantábrica en su contexto peninsular y pirenaico. Monografías de Altamira 23, Museo Nacional y Centro de Investigación de Altamira. Madrid: 476-491.

Iriarte-Chiapusso, M. ${ }^{\text {a }}$ J.; Yravedra, J.; Álvarez-Alonso, D.; Álvarez-Fernández, E.; Aparicio, M. ${ }^{\mathrm{a}}$ T.; Arrizabalaga, A.; Elorza, M.; Gabriel, S.; Jordá Pardo, J. F.; Sesé, C. y Uzquiano, P. (en prensa): "El contexto paleoambiental de las ocupaciones humanas de la cueva de Coímbre (Peñamellera Alta, Asturias), durante el Pleistoceno superior". En D. Álvarez-Alonso y J. Yravedra (eds.): La cueva de Coímbre (Peñamellera Alta, Asturias). Ocupaciones humanas en el valle del Cares durante el Paleolítico Superior. Ed. Fundación María Cristina Masaveu Peterson.
Jordá Cerdá, F. 1963: “El Paleolítico Superior cantábrico y sus industrias". Saitabi 13: 3-22.

Jordá Cerdá, F. 1969: “Los comienzos del Paleolítico Superior en Asturias". En Simposio Internacional conmemorativo del Centenario del descubrimiento del primer hombre de Cro-Magnon [Islas Canarias (Gran Canaria, Tenerife y La Palma) 1969]: 280321. Islas Canarias.

Jordá Cerdá, F. 1976: Guía de las cuevas prehistóricas asturianas. Colección popular asturiana 11, Ayalga. Salinas (Asturias).

Jordá Pardo, J. F.; Álvarez-Alonso, D. e Iriarte Chiapusso, M' . J. 2014: "Una aproximación geoarqueológica al hábitat humano pleistoceno del occidente cantábrico (Asturias, norte de España)". En D. Álvarez-Alonso (ed.): Los grupos cazadores-recolectores paleolíticos del occidente cantábrico. UNED-Asturias: 67-102.

Martínez, L. y Rasilla, M. de la 2013: “El Gravetiense en Asturias: revisión y novedades". En C. de las Heras, J. A. Lasheras, A. Arrizabalaga y M. de la Rasilla (eds.): Pensando el Gravetiense: nuevos datos para la región cantábrica en su contexto peninsular y pirenaico. Monografías de Altamira 23, Museo Nacional y Centro de Investigación de Altamira. Madrid: 291-304.

Moure, J. A. y Gil, G. 1972: "Noticia preliminar sobre los nuevos yacimientos de arte rupestre descubiertos en Peñamellera Alta (Asturias)". Trabajos de Prehistoria 29: 245-254.

Moure, J. A. y Gil, G. 1974: "La cueva de Coimbre, en Peñamellera Alta (Asturias)". Boletín del Instituto de Estudios Asturianos 82: 505-528.

Pinto-Llona, A.; Clark G.; Karkanas, P.; Blackwell, B.; Skinner, A. R.; Andrews, P.; Reed, K.; Miller, A.; Macías-Rosado, R. y Vakiparta, J. 2012: "The Sopeña Rockshelter, a New Site in Asturias (Spain) bearing evidence on the Middle and Early Upper Palaeolithic in Northern Iberia". Munibe 63: 45-79.

Rasilla, M. de la 1990: "Cueto de la Mina: campañas 1981-1986". Excavaciones Arqueológicas en Asturias: 1983-86,Servicio de Publicaciones del Principado de Asturias. Oviedo: 79-86.

Rasilla, M. de la y Hoyos, M. 1988: "Nuevos datos sobre el yacimiento de Cueto de la Mina (Posada de Llanes, Asturias): avance de las campañas de 19811985". Noticiario Arqueológico Hispánico 30: 7-20.

Rasilla Vives, M. de la y Santamaría, D. 2006: El Gravetiense del abrigo de Cueto de la Mina (Posada de Llanes, Asturias) . En J. M. Maíllo y E. Baquedano (eds.): Miscelánea en homenaje a Victoria Cabrera I. Zona Arqueológica 7, Museo Arqueológico Regional. Madrid: 422-439.

Rasilla, M. de la y Straus, L. G. 2004: “El poblamiento en la región cantábrica en torno al Último Máximo Glacial: Gravetiense y Solutrense". En M. Á. Fano (ed.): Las sociedades del Paleolítico en la región cantábrica. Kobie 8: 209-242.

Trab. Prehist., 74, N. ${ }^{\circ}$ 1, enero-junio 2017, pp. 47-67, ISSN: 0082-5638

doi: $10.3989 /$ tp.2017.12183 
Rasines, P. y Muñoz, E. 2013: "Los niveles gravetienses del abrigo del Cuco (Castro Urdiales, Cantabria)". En C. de las Heras, J. A. Lasheras, A. Arrizabalaga y M. de la Rasilla (eds.): Pensando el Gravetiense: nuevos datos para la región cantábrica en su contexto peninsular y pirenaico. Monografías de Altamira 23, Museo Nacional y Centro de Investigación de Altamira. Madrid: 241-263.

Ríos, J.; Peña, P. de la y San Emeterio-Gómez, A. 2011: "Estudio de las industrias líticas y óseas de la cueva de Aitzbitarte III (Zona de la entrada)". En J. Altuna, K. Mariezkurrena y J. Ríos (eds.): $\mathrm{Ocu}$ paciones humanas en Aitzbitarte III (País Vasco). 33.600-18.400 BP (Zona de entrada a la cueva). Centro de Patrimonio Cultural del Gobierno Vasco, Vitoria-Gasteiz: 79-352.

Sáenz de Buruaga, A. 2008: "Cueva de Aldatxarren”. Arkeoikuska 2007: 367-374.

Shackleton, N.J. y Opdyke, N.D., 1973: “Oxygen isotope and paleomagnetic stratigraphy of equatorial Pacific core V28-238: oxigen isotope temperature and ice volumes on $10^{5}$ year and $10^{6}$ year scale". Quaternary Research 3: 39-55.

Tarriño, A.; Duarte, E.; Santamaría, D.; Martínez, L.; Fernández de la Vega, J.; Suárez, P.; Rodríguez, V.; Forcelledo, E. y Rasilla, M. de la 2013: "El sílex de Piloña. Caracterización de una nueva fuente de materia prima lítica en la Prehistoria de Asturias". En M. de la Rasilla (ed.): F. Javier Fortea Pérez. Universitatis Ovetensis Magister. Estudios en homenaje. Universidad de Oviedo/ Ménsula ed. Oviedo: 115-132.

Utrilla, P. 1981. El Magdaleniense inferior y medio en la costa cantábrica. Centro de Investigación y Museo de Altamira 4. Santander.

Uzquiano, P. 2014: "Wood resource exploitation by Cantabrian late Upper Palaeolithic groups (N Spain) in relation to MIS 2 vegetation dynamics". Quaternary International 337: 154-162.

Vercoutère, C.; San Juan-Foucher C.; Foucher P. 2013: "Faune gravettienne de Gargas (Hautes-Pyrénées, France): apports récents de l'archéozoologie à l'étude d'un 'sanctuaire' pariétal". En C. de las Heras, J.-A. Lasheras, A. Arrizabalaga, M. de la Ra- silla (eds.): Pensando el Gravetiense: nuevos datos para la región cantábrica en su contexto peninsular y pirenaico. Monografías de Altamira 23, Museo Nacional y Centro de Investigación de Altamira. Madrid: 538-552.

Vega del Sella, conde de la 1916: Paleolítico de Cueto de la Mina (Asturias). Comisión de Investigaciones Paleontológicas y Prehistóricas, Memoria 13. Madrid.

Wood, R. E.; Arrizabalaga, A.; Camps, M.; Fallon, S.; Iriarte-Chiapusso, M. J.; Jones, R.; Maroto, J.; Rasilla, M. de la; Santamaría, D.; Soler, J.; Soler, N.; Villaluenga, A. y Higham, T. F. G. 2014: "The chronology of the earliest Upper Palaeolithic in northern Iberia: New insights from L'Arbreda, Labeko Koba and La Viña". Journal of Human Evolution 69: 91-109.

Yravedra, J.; Álvarez-Alonso, D.; Andrés-Chain, M. de; Estaca, V.; López, P.; Arrizabalaga, A.; Iriarte, M. a J.; Jordá, J. F.; Elorza, M. y Uzquiano, P. 2017: "Selection and exploitation of macro-vertebrates resources during the Upper palaeolithic in northern Spain. New evidences from the Coímbre cave (Peñamellera Alta, Asturias)". Oxford Journal of Archaeology 36 (4).

Yravedra, J.; Álvarez-Alonso, D.; Estaca, V.; López, P.;

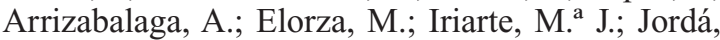
J. F.; Sesé, C. y Uzquiano, P. 2016: "New evidence of bones used as fuel in the Gravettian Coímbre cave, northern Iberian peninsule". Archaeological and Anthropological Sciences. doi:10.1007/s12520016-0317-0.

Yravedra, J.; Baena, J.; Arrizabalaga, A. e Iriarte, M. J. 2005: "El empleo de material óseo como combustible durante el Paleolítico Medio y Superior en el Cantábrico. Observaciones experimentales”. En J. A. Lasheras y R. Montes (eds.): Neandertales cantábricos. Estado de la cuestión. Museo Nacional de Altamira 20, Museo Nacional y Centro de Investigación de Altamira. Santander: 369-383.

Yravedra, J. y Uzquiano, P. 2013: "Burned bone assemblages from El Esquilleu cave (Cantabria, Northern Spain) deliberate use for fuel or systematic disposal of organic waste?". Quaternary Science Reviews 68:175-190. 